\title{
Expectational Equilibria in Many-to-one Matching Models with Contracts - A Reformulation of Competitive Equilibrium
}

\author{
Citation for published version (APA): \\ Herings, P. J-J. (2020). Expectational Equilibria in Many-to-one Matching Models with Contracts - A \\ Reformulation of Competitive Equilibrium. Maastricht University, Graduate School of Business and \\ Economics. GSBE Research Memoranda No. 018 https://doi.org/10.26481/umagsb.2020018
}

Document status and date:

Published: 02/07/2020

DOI:

10.26481/umagsb.2020018

Document Version:

Publisher's PDF, also known as Version of record

\section{Please check the document version of this publication:}

- A submitted manuscript is the version of the article upon submission and before peer-review. There can be important differences between the submitted version and the official published version of record. People interested in the research are advised to contact the author for the final version of the publication, or visit the DOI to the publisher's website.

- The final author version and the galley proof are versions of the publication after peer review.

- The final published version features the final layout of the paper including the volume, issue and page numbers.

Link to publication

\footnotetext{
General rights rights.

- You may freely distribute the URL identifying the publication in the public portal. please follow below link for the End User Agreement:

www.umlib.nl/taverne-license

Take down policy

If you believe that this document breaches copyright please contact us at:

repository@maastrichtuniversity.nl

providing details and we will investigate your claim.
}

Copyright and moral rights for the publications made accessible in the public portal are retained by the authors and/or other copyright owners and it is a condition of accessing publications that users recognise and abide by the legal requirements associated with these

- Users may download and print one copy of any publication from the public portal for the purpose of private study or research.

- You may not further distribute the material or use it for any profit-making activity or commercial gain

If the publication is distributed under the terms of Article $25 \mathrm{fa}$ of the Dutch Copyright Act, indicated by the "Taverne" license above, 
P. Jean-Jacques Herings

Expectational Equilibria in Manyto-one Matching Models with Contracts - A Reformulation of Competitive Equilibrium

$\mathrm{RM} / 20 / 018$

ISSN: $2666-8807$

\section{GSBE}

Maastricht University School of Business and Economics 


\title{
Expectational Equilibria in Many-to-one Matching Models with Contracts - A Reformulation of Competitive Equilibrium
}

\author{
P. Jean-Jacques Herings ${ }^{* \dagger}$
}

June 22, 2020

\begin{abstract}
We introduce the notion of expectational equilibrium in a very general specification of the many-to-one matching with contracts model. The endogenous variables in an expectational equilibrium are expectations about tradable contracts. Expectational equilibrium outcomes are equivalent to stable outcomes. Substitutability of preferences is a sufficient condition for existence. Expectational equilibrium unifies all the other approaches used in the literature so far, in particular Walrasian equilibrium, Drèze equilibrium, and market clearing cutoffs. It also applies to cases where contracts do not involve money as well as cases where there is a smallest monetary unit of account.
\end{abstract}

Keywords: Matching, Competitive Equilibrium, Stable Outcomes, Expectational Equilibrium.

JEL CODES: C71, C78, D45, D51.

${ }^{*}$ P.J.J. Herings, Department of Economics, Maastricht University, P.O. Box 616, 6200 MD, Maastricht, The Netherlands. P.Herings@maastrichtuniversity.nl

${ }^{\dagger}$ Comments and suggestions by Yu Zhou are greatly appreciated. 


\section{Introduction}

There is a longstanding tradition in the economics literature to study the equivalence between competitive equilibria and cooperative solution concepts. Such equivalence results provide cooperative foundations for the equilibrium approach and equilibrium foundations for the cooperative approach. A particular branch of the literature studies this question within a matching framework.

A first paper that establishes an equivalence result in the matching set-up is Shapley and Shubik (1971) in their study of the assignment model. Kaneko (1982) extends this model to cover the case where utility functions are not assumed to be quasi-linear. Kelso and Crawford (1982) study a model of job matching with salaries and find an equivalence result for the many-to-one case. Hatfield, Kominers, Nichifor, Ostrovsky, and Westkamp (2013) obtain an equivalence result for trading networks where agents have quasi-linear utility functions. Fleiner, Jagadeesan, Jankó, and Teytelboym (2019) further generalize the analysis to cover general utility functions. They find an equivalence between competitive equilibrium and a cooperative solution concept called trail-stability. The papers in this stream of the literature rely on the existence of a commodity money that can be transferred between agents without limits.

In important applications like school choice, money is not part of the contract. In other applications it is, but is subject to price controls. Finally, in reality there is always a smallest unit of account, which rules out continuous transfers. For the school choice model, Azevedo and Leshno (2016) demonstrate the equivalence between a market clearing cutoff and a stable outcome. For models with price rigidities, the marriage problem of Gale and Shapley (1962) being a special case, Herings (2018) shows an equivalence between Drèze equilibria and stable outcomes.

This paper studies a very general specification of the many-to-one matching with contracts model. The set of contracts is allowed to be uncountable. Preferences can have indifferences and need not be substitutable. For many of our results, they need not even be continuous. An important special case is Hatfield and Milgrom (2005), where the set of contracts is finite and preferences are assumed to be strict.

The paper introduces the notion of an expectational equilibrium. At an expectational equilibrium, agents hold expectations about the tradability of contracts, i.e., about the willingness of a contract's counterparty to sign it. When agents expect that certain trades cannot be made, then we refer to this as rationing constraints. Given such expectations, all agents optimize and choose an optimal bundle of contracts. At equilibrium expectations are rational in the sense that if an agents expects to be rationed in a particular contract, then the counterparty of the contract optimally chooses not to sign it, even though that agent does not experience rationing. In other words, at equilibrium, for each contract, at 
most one side expects rationing. ${ }^{1}$

As in the model of Hatfield and Milgrom (2005), contracts may or may not involve the delivery of money. Our notion of expectational equilibrium applies to all these cases and does therefore not explicitly depend on prices. In a monetary economy, all contracts specify an amount of money that the buyer of a contract has to pay to its seller. By analyzing the contracts that are actively traded in an equilibrium, it is possible to infer the equilibrium prices. $^{2}$

As an illustration, consider the standard textbook case of partial equilibrium with finitely many buyers and sellers, each with unit demand and unit supply, who trade a perfectly homogeneous good. A contract consists of a buyer-seller pair and an amount of money. Buyers and sellers form expectations about contracts that are tradable. Among the contracts for which the buyer does not expect rationing, the one with the lowest price is demanded, conditional on this price being below the reservation value of the buyer. Similarly, among the contracts for which the seller does not expect rationing, the one with the highest price is demanded, conditional on this price being above the reservation value of the seller.

In an expectational equilibrium for the textbook case, for the effectuation of a contract between a particular buyer and seller, both should expect this is the best price that can be obtained. Next, it follows that all contracts that are signed in equilibrium have the same price. Otherwise, it must be that a seller who is selling low and a buyer who is buying high both expect rationing of the contract between them for all prices in between the low and the high price. But that would contradict that at equilibrium at most one side expects rationing for a given contract. The common price should be at least equal to the reservation price of each buyer who does not trade at equilibrium and should also be greater than or equal to the reservation price of each seller that does trade. Moreover, the common price should be at most equal to the reservation price of each buyer who trades at equilibrium and should also be less than or equal to the reservation price of each seller that does not trade. The common price is therefore a market clearing price in the usual sense of the word.

We refer to a free-contracting monetary economy if each possible trade can be accom-

\footnotetext{
${ }^{1}$ Richter and Rubinstein (2015) define the notions of unrestricted equilibrium and primitive equilibrium for abstract economies. Their approach is based on an abstract notion of convexity and is quite different from the one in this paper. A common feature with this paper is to think of a competitive equilibrium as a method of creating harmony in an interactive situation with self-interested agents.

${ }^{2}$ In a very different set-up, the one of general equilibrium theory with incomplete assets markets that allows for default and punishment, Dubey, Geanakoplos and Shubik (2005) show how competitive equilibrium can be used to endogenously select the promises, default penalties, and quantity constraints of actively traded assets.
} 
panied by an arbitrary amount of money. This implies that money is perfectly divisible and that there are no legal restrictions like minimum wages that put bounds on monetary transfers. We show that in a free-contracting monetary economy the set of expectational equilibrium outcomes coincides with the set of Walrasian equilibrium outcomes. In the more general case of price controls, where money is perfectly divisible but monetary transfers are potentially subject to lower and upper bounds, expectational equilibrium outcomes are shown to coincide with Drèze equilibrium outcomes.

Most papers in the matching literature use cooperative solution concepts to study matching outcomes. For many-to-one matching models, typical concepts are pairwise stability, stability, the core, and the strong core. Without putting any additional assumptions on the primitives, we find that expectational equilibrium outcomes coincide with stable outcomes. In particular this holds for preferences that may exhibit indifferences, discontinuities, and may not be substitutable and for sets of contracts that could be countably infinite and need not be compact or closed. Expectational equilibrium therefore singles out the set of stable outcomes in many-to-one matching models.

Existence of expectational equilibria is guaranteed whenever stable outcomes are known to exist. A well-known sufficient condition is substitutability as introduced in Kelso and Crawford (1982) in terms of changes in an agent's demand as prices change. We follow the approach of Roth (1984) and formulate a choice-theoretic definition of substitutability. As in Sotomayor (1999), we allow preferences to have indifferences. Our notion of substitutability needs to hold for finite subsets of the set of contracts. More precisely, if a finite set of contracts from which the agent can choose expands, then, given any optimal choice for the original set of contracts, the agent has an optimal choice in the expanded set that does not involve contracts that were available but not chosen before. Together with continuity of preferences, substitutability is sufficient to obtain existence of an expectational equilibrium. Our existence proof involves an adjustment process in the style of Gale and Shapley (1962), Crawford and Knoer (1981), Kelso and Crawford (1982), Demange, Gale and Sotomayor (1986), and Hatfield and Milgrom (2005).

The existence results also opens up avenues for equilibrium existence for monetary economies where money is not perfectly divisible and prices are denominated in a smallest monetary unit of account. An important application concerns the analysis of the influence of the tick size in financial markets, see Plott, Roll, Seo, and Zhao (2019). In such models it is still true that Walrasian equilibrium outcomes are expectational equilibrium outcomes. However, Walrasian equilibrium outcomes may fail to exist, as is easily demonstrated in a simple example of partial equilibrium where supply and demand curves intersect at a price which is not a multiple of the smallest unit of account. A more general set-up is provided by the assignment model of Shapley and Shubik (1971) in the presence of a smallest monetary 
unit of account. Since that model satisfies substitutability, expectational equilibria always exist, whereas Walrasian equilibria may not.

Section 2 introduces the notion of expectational equilibrium in a many-to-one matching model with contracts. It shows how that model directly incorporates the marriage problem (Gale and Shapley, 1962), the assignment model (Shapley and Shubik, 1971), matching under price controls (Herings, 2018), job matching with salaries (Kelso and Crawford, 1982), and matching with contracts (Hatfield and Milgrom, 2005) as special cases. In Section 3 we show how in the model of school choice studied by Abdulkadiroğlu, Che, and Yasuda (2015) and Azevedo and Leshno (2016), expectational equilibrium outcomes correspond to market clearing cutoffs. Section 4 demonstrates the equivalence between expectational equilibrium outcomes and stable outcomes and explains that under the weak assumptions we have made, stable outcomes may not coincide with pairwise stable outcomes, core outcomes, or strong core outcomes. Expectational equilibria are shown to exist in Section 5 when preferences are substitutable and appropriate continuity assumptions are in place. Section 6 studies monetary economies and demonstrates that any Walrasian equilibrium is an expectational equilibrium. The reverse implication is shown to hold for free-contracting monetary economies. Section 7 considers the set-up of monetary economies subject to price controls and demonstrates the equivalence to Drèze equilibrium outcomes. Section 8 contains the conclusion.

\section{Expectational Equilibrium}

There is a finite set of firms $F$, a finite set of workers $W$, and a set of contracts $\bar{Y}$. The set $\bar{Y}$ is not necessarily finite and also uncountable sets $\bar{Y}$ are permitted. The set of agents is then $I=F \cup W$. Each contract $y \in \bar{Y}$ is bilateral, so is associated with one firm $f(y) \in F$ and one worker $w(y) \in W$. A worker $w \in W$ signs at most one contract, whereas a firm can sign any number of contracts, though not more than one contract with any given worker.

For a given set of contracts $Y \subset \bar{Y}$, the set of contracts involving firm $f$ is equal to $Y^{f}=\{y \in Y \mid f(y)=f\}$ and the set of contracts involving worker $w$ equals $Y^{w}=\{y \in$ $Y \mid w(y)=w\}$. The sets $f(Y)=\{f \in F \mid \exists y \in Y$ such that $f(y)=f\}, w(Y)=\{w \in W \mid$ $\exists y \in Y$ such that $w(y)=w\}$, and $i(Y)=\{i \in I \mid \exists y \in Y$ such that $f(y)=i$ or $w(y)=i\}$ are the sets of firms, workers, and agents involved in $Y$, respectively.

The consumption set $X^{f}$ of a firm $f \in F$ is equal to

$$
X^{f}=\left\{Y^{f} \subset \bar{Y}^{f} \mid \forall y, y^{\prime} \in Y^{f} \text { with } y \neq y^{\prime} \text { it holds that } w(y) \neq w\left(y^{\prime}\right)\right\} .
$$

The consumption set $X^{f}$ consists of sets of contracts involving firm $f$ that associate at most one contract with any given worker $w$. A firm $f$ has to choose an element of $X^{f}$, i.e., 
has to choose a set of workers and sign a contract with each one of them. The empty set is an element of $X^{f}$, so the firm may choose not to sign any contract at all. The consumption set $X^{w}$ of a worker $w \in W$ is given by

$$
X^{w}=\left\{Y^{w} \subset \bar{Y}^{w}|| Y^{w} \mid \leq 1\right\},
$$

so $X^{w}$ consists of the singleton subsets of $\bar{Y}^{w}$ and the empty set.

The preferences of an agent $i \in I$ are represented by a utility function $u^{i}: X^{i} \rightarrow \mathbb{R}$. Without loss of generality it is assumed that $u^{i}(\emptyset)=0$. When certain combinations of contracts in $X^{f}$ are not feasible for firm $f$, then it suffices to assign a negative utility level to such a set. There are no further assumptions on the utility functions, so preferences may exhibit indifferences and are not required to satisfy substitutability or continuity assumptions.

A set of contracts $A \subset \bar{Y}$ is an outcome if for every $i \in I$ it holds that $A^{i} \in X^{i}$. So in particular, every worker signs a single contract or no contract. A firm may sign many contracts, but at most one contract with any given worker. Let $\mathcal{A}$ denote the set of all outcomes. Utility functions are extended to outcomes in $\mathcal{A}$ by defining, for every $A \in \mathcal{A}$, $u^{i}(A)=u^{i}\left(A^{i}\right)$.

The set of contracts and utility functions together define an economy $\mathcal{E}=\left(\bar{Y},\left(u^{i}\right)_{i \in I}\right)$.

We illustrate now how a number of important models studied in the literature before fit in as special cases.

EXAMPLE 2.1: Gale and Shapley (1962), marriage problem.

A community consists of the same number of men and women. Each person strictly ranks those of the oppositive sex in accordance with his or her preferences for a marriage partner. Monetary transfers are not allowed. We define $F$ as the set of men, $W$ as the set of women, and $\bar{Y}=F \times W$ as the set of contracts. A marriage contract corresponds to a pair of a man and a woman. Utility functions are now specified in accordance with each person's ranking of the partners of opposite sex and the prospect of remaining single. To guarantee that a man marries at most one woman, it is sufficient to take, for every $f \in F$, for every $Y^{f} \subset \bar{Y}$ that has at least two elements, $u^{f}\left(Y^{f}\right)<0$.

Example 2.1 does not offer the men and the women the possibility to make monetary transfers when contracting. The polar opposite is illustrated in the next example, where unbounded monetary transfers are allowed for.

EXAMPLE 2.2: Shapley and Shubik (1971), assignment model.

In the real estate market there is a finite set of homeowners $W$ as well as a finite set of prospective purchasers $F$. Homeowner $w \in W$ values his or her house at $c_{w}$ dollars, 
while purchaser $f \in F$ values the same house at $h_{f w}$ dollars. There are no restrictions on monetary transfers between homeowners and prospective purchasers. The set of contracts is equal to $\bar{Y}=F \times W \times \mathbb{R}$. A contract $y=(f, w, m) \in \bar{Y}$ involves the sale of the house of homeowner $w$ to buyer $f$ against an amount of money $m$. The utility of a buyer $f \in F$ of a contract $(f, w, m) \in \bar{Y}$ is given by

$$
u^{f}(\{(f, w, m)\})=h_{f w}-m
$$

and the utility of a seller $w \in W$ is equal to

$$
u^{w}(\{(f, w, m)\})=m-c_{w} .
$$

In the model of Shapley and Shubik (1971), each buyer is interested in buying at most one house. We therefore define, for every $f \in F$, for every $Y^{f} \subset \bar{Y}$ that has at least two elements, $u^{f}\left(Y^{f}\right)<0$.

The next example is based on Herings (2018) and covers Examples 2.1 and 2.2 as special cases by introducing price controls. It also contains the assignment model with price controls as studied by Talman and Yang (2008) and Andersson and Svensson (2014) as a special case.

EXAMPLE 2.3: Herings (2018), matching under price controls.

There is a finite set of buyers $F$ and a finite set of sellers $W$ who trade commodities in a finite set $L$ against money. The amount of money involved in a contract is subject to price controls. To be more precise, the price of a commodity $\ell \in L$ is subject to a price floor $\underline{p}_{\ell} \in\{-\infty\} \cup \mathbb{R}$ and a price ceiling $\bar{p}_{\ell} \in \mathbb{R} \cup\{+\infty\}$ such that $\underline{p}_{\ell} \leq \bar{p}_{\ell}$. Some agents may not be able to trade certain commodities. This is captured by a set of feasible trades $T \subset F \times W \times L$. The resulting set of contracts is then equal to

$$
\bar{Y}=\left\{(f, w, \ell, m) \in F \times W \times L \times \mathbb{R} \mid(f, w, \ell) \in T \text { and } \underline{p}_{\ell} \leq m \leq \bar{p}_{\ell}\right\} .
$$

In the model of Herings (2018), each buyer is interested in buying at most one commodity. We therefore define, for every $f \in F$, for every $Y^{f} \subset \bar{Y}$ that has at least two elements, $u^{f}\left(Y^{f}\right)<0$. The concept of a commodity contains all utility relevant information. For a buyer the utility of a commodity does not depend on the agent delivering it and for a seller the utility of a commodity is independent of the identity of its buyer. By an appropriate definition of a commodity, this assumption is without loss of generality. All utility functions are assumed to be continuous and strongly monotonic in $m$, decreasing in $m$ for buyers and increasing in $m$ for sellers. There are limits to the monetary transfers buyers are willing to make for commodities without price ceilings. For every $f \in F$, for every 
$\ell \in L$ such that $\bar{p}_{\ell}=+\infty$, there is $m \in \mathbb{R}$ such that $u^{f}(\{(f, w, \ell, m)\}) \leq u^{f}(\emptyset)$. There are limits to the monetary transfers sellers are willing to make for commodities without price floors. For every $w \in W$, for every $\ell \in L$ such that $\underline{p}_{\ell}=-\infty$, there is $m \in \mathbb{R}$ such that $u^{w}(\{(f, w, \ell, m)\}) \leq u^{w}(\emptyset)$. Appropriate choices for the price controls reduce Examples 2.1 and 2.2 to special cases of this example.

Examples 2.1, 2.2, and 2.3 are examples of one-to-one matching. We now present a many-to-one matching model.

EXAMPLE 2.4: Kelso and Crawford (1982), job matching with salaries.

There is a finite set of firms $F$ and a finite set of workers $W$. Each firm hires as many workers as it wishes, but each worker is allowed to work only at one firm. The set of contracts is equal to $\bar{Y}=F \times W \times \mathbb{R}$. A contract $y=(f, w, m) \in \bar{Y}$ involves a labor contract between firm $f$ and worker $w$ against a salary $m$. The utility $u^{w}(\{(f, w, m)\})$ of worker $w \in W$ is assumed to be continuous and strictly increasing in $m$. The gross product of a firm $f \in F$ that hires a set of workers $S \subset W$ is equal to $v^{f}(S)$. Let $Y^{f} \in X^{f}$ be a set of contracts involving the workers in $S$, so $w\left(Y^{f}\right)=S$, and let the salary of worker $w \in S$ as specified in the contract be equal to $m_{w}$. The utility firm $f$ derives from signing the contracts in $Y^{f}$ is given by

$$
u^{f}\left(Y^{f}\right)=v^{f}(S)-\sum_{w \in S} m_{w}
$$

The utility function $u^{f}$ is assumed to satisfy the condition of gross substitutes to be explained next. Let $\underline{m}, \underline{m}^{\prime} \in \mathbb{R}^{W}$ with $\underline{m} \leq \underline{m}^{\prime}$ be vectors of workers' salaries and let $Y^{f}=\left\{(f, w, m) \in \bar{Y} \mid m=\underline{m}_{w}\right\}$ and $Y^{\prime f}=\left\{(f, w, m) \in \bar{Y} \mid m=\underline{m}_{w}^{\prime}\right\}$ be sets of contracts specifying salaries $\underline{m}$ and $\underline{m}^{\prime}$ for the workers, respectively. For a set of workers $S \subset W$, the set $U(S)=\left\{w \in S \mid \underline{m}_{w}=\underline{m}_{w}^{\prime}\right\}$ contains those workers whose salaries did not change between $\underline{m}$ and $\underline{m}^{\prime}$. Let $\mathcal{Y}^{f}$ contain all the solutions to

$$
\arg \max _{A^{f} \subset Y^{f}} u^{f}\left(A^{f}\right)
$$

and let $\mathcal{Y}^{\prime f}$ contain all the solutions to

$$
\arg \max _{A^{f} \subset Y^{\prime f}} u^{f}\left(A^{f}\right)
$$

The condition of gross substitutes is satisfied if for every $A^{f} \in \mathcal{Y}^{f}$ there exists $A^{\prime f} \in \mathcal{Y}^{\prime f}$ such that $U\left(w\left(A^{f}\right)\right) \subset w\left(A^{\prime f}\right)$. Gross substitutes requires that increases in other workers' salaries does not cause a firm to fire a worker whose salary has not risen. 
Shapley and Shubik (1971) and Kelso and Crawford (1982) observe that there is an equivalence between the notion of competitive equilibrium and the notion of stability in their respective models, explained in Example 2.2 and 2.4, respectively. The appropriate notion of competitive equilibrium for the model of Example 2.3 has been introduced in Herings (2018). That notion also applies to the model of Gale and Shapley (1962) discussed in Example 2.1. The next example concerns a matching model with contracts. Unlike the previous examples, there is no known notion of competitive equilibrium that applies to this model.

ExAMPLE 2.5: Hatfield and Milgrom (2005), matching with contracts.

There is a finite set of hospitals $F$ and a finite set of doctors $W$. Each hospital hires as many doctors as it wishes, but each doctor is allowed to work only at one hospital. The set of contracts is a finite set $\bar{Y}$. Preferences are assumed to be strict. For every $f \in F$, for every $Y^{f}, Y^{\prime f} \in X^{f}$ such that $Y^{f} \neq Y^{\prime f}$ it holds that $u^{f}\left(Y^{f}\right) \neq u^{f}\left(Y^{\prime f}\right)$. For every $w \in W$, for every $Y^{w}, Y^{w} \in X^{w}$ such that $Y^{w} \neq Y^{w}$ it holds that $u^{w}\left(Y^{w}\right) \neq u^{w}\left(Y^{w}\right)$. The utility function $u^{f}$ is assumed to satisfy the condition of substitutes to be explained next. Let $Y^{\prime}, Y^{\prime \prime} \subset \bar{Y}$ with $Y^{\prime} \subset Y^{\prime \prime}$ be sets of contracts. Let $A^{\prime f}$ be the unique solution to

$$
\arg \max _{A^{f} \subset Y^{\prime}} u^{f}\left(A^{f}\right)
$$

and let $A^{\prime \prime}$ be the unique solution to

$$
\arg \max _{A^{f} \subset Y^{\prime \prime}} u^{f}\left(A^{f}\right)
$$

Next, we define the sets of rejected contracts as $R^{f}\left(Y^{\prime}\right)=Y^{\prime} \backslash A^{\prime f}$ and $R^{f}\left(Y^{\prime \prime}\right)=Y^{\prime \prime} \backslash A^{\prime \prime} f$. The condition of substitutes is satisfied if $R^{f}\left(Y^{\prime}\right) \subset R^{f}\left(Y^{\prime \prime}\right)$.

Under the assumption of substitutability on the preferences, Echenique (2012) has shown how Example 2.5 can be embedded as a special case of Example 2.4.

We now define a notion of equilibrium that applies to the many-to-one matching with contracts model as introduced in this section and thereby to all the examples discussed so far, so in particular to Example 2.5 introducing the model of Hatfield and Milgrom (2005).

Let $Q \subset \bar{Y}$ denote a set of rationing constraints as applying to firms. If a contract $y$ belongs to $Q$, then firm $f(y)$ expects that it is not possible to trade contract $y$. The reason is that firm $f(y)$ expects that contract $y$ does not belong to the demand set of worker $w(y)$. Similarly, let $R \subset \bar{Y}$ denote a set of rationing constraints as applying to workers. If a contract $y$ belongs to $R$, then worker $w(y)$ expects that it is not possible to trade contract $y$. The reason is that worker $w(y)$ expects that contract $y$ does not belong to the demand set of firm $f(y)$. Both $Q$ and $R$ are determined endogenously in an expectational 
equilibrium as defined in Definition 2.6. At equilibrium, the expectations embodied in $Q$ and $R$ are rational.

Given a set of rationing constraints $Q$, the budget set of firm $f \in F$ is given by

$$
\beta^{f}\left(Q^{f}\right)=\left\{A^{f} \in X^{f} \mid A^{f} \cap Q^{f}=\emptyset\right\} .
$$

The demand correspondence $\delta^{f}$ of firm $f$ is defined by

$$
\delta^{f}\left(Q^{f}\right)=\arg \max _{A^{f} \in \beta^{f}\left(Q^{f}\right)} u^{f}\left(A^{f}\right) .
$$

Given a set of rationing constraints $R$, the budget set of worker $w \in W$ is given by

$$
\beta^{w}\left(R^{w}\right)=\left\{A^{w} \in X^{w} \mid A^{w} \cap R^{w}=\emptyset\right\}
$$

The demand correspondence $\delta^{w}$ of worker $w$ is defined by

$$
\delta^{w}\left(R^{w}\right)=\arg \max _{A^{w} \in \beta^{w}\left(R^{w}\right)} u^{w}\left(A^{w}\right) .
$$

Definition 2.6: An expectational equilibrium of the economy $\mathcal{E}=\left(\bar{Y},\left(u^{i}\right)_{i \in I}\right)$ is an element $\left(A^{*}, Q^{*}, R^{*}\right) \in \mathcal{A} \times 2^{\bar{Y}} \times 2^{\bar{Y}}$ such that:

1. For every $f \in F, A^{* f} \in \delta^{f}\left(Q^{* f}\right)$.

2. For every $w \in W, A^{* w} \in \delta^{w}\left(R^{* w}\right)$.

3. $Q^{*} \cap R^{*}=\emptyset$.

The first two conditions in Definition 2.6 correspond to standard optimization by firms and workers. A firm $f \in F$ only needs to know which contracts do not belong to $Q^{f}$, i.e., the contracts for which it expects that trade is possible, and does not need to consider the other agents in making its choices. A worker $w \in W$ only needs to know which contracts do not belong to $R^{w}$, i.e., the contracts for which the worker expects that trade is possible, and does not need to consider the other agents when making a choice. From Conditions 1 and 2 of an expectational equilibrium, it follows that $A^{*} \cap Q^{*}=\emptyset$ and $A^{*} \cap R^{*}=\emptyset$.

Condition 3 of Definition 2.6 expresses that markets are transparent. For a given contract, it cannot be that both sides of the market simultaneously expect to be rationed. This condition also guarantees that expectations of firms and workers are rational. If, for instance, $y \in Q^{* f}$, so the firm expects rationing for contract $y$, i.e., expects no demand for contract $y$ by worker $w=w(y)$, then $y \notin R^{* w}$ by Condition 3 of Definition 2.6. Worker $w$ is therefore free to demand contract $y$, but chooses not to do so, since $y \in Q^{* f}$ implies $y \notin A^{*}$ and therefore $y \notin A^{* w}$. The firm therefore correctly anticipates rationing for contract $y$. The same kind of reasoning applies to contracts $y \in R^{* w}$. 
There is no need for an explicit market clearing condition. Since any contract $y \in A^{*}$ involves a firm $f=f(y)$ and a worker $w=w(y)$, market clearing follows from $A^{* f} \in$ $\delta^{* f}\left(Q^{* f}\right)$ and $A^{* w} \in \delta^{* w}\left(R^{* w}\right)$.

Expectational equilibria do not rely on the presence of money as part of the contract. This makes the concept particularly suitable for application to the marriage problem of Gale and Shapley in Example 2.1 and the matching with contracts model of Hatfield and Milgrom (2005). We discuss the application of expectational equilibrium to the model of school choice studied in Abdulkadiroğlu, Che, and Yasuda (2015) and Azevedo and Leshno (2016) in the next section and show how expectational equilibria are related to their notion of a market clearing cutoff.

\section{An Application to School Choice}

Azevedo and Leshno (2016) consider a model of school choice, where the set of colleges is finite and the set of students is either finite or a continuum. Here we present their analysis of demand and supply for the case with a finite set of students and show how it is related to expectational equilibrium. The set of contracts $\bar{Y}$ is identified with $F \times W$ and corresponds to all possible pairs of a college and a student. A student $w \in W$ has strict preferences over the colleges, which are represented by the utility function $u^{w}$, where $u^{w}(\{(f, w)\})>0$ corresponds to the utility provided by college $f \in F$. A college $f \in F$ has a capacity of $q_{f}$ seats. The preferences of college $f$ over students are determined by the score $u^{f}(\{(f, w)\}) \in(0,1]$ college $f$ assigns to student $w$. The preferences of the colleges are assumed to be strict and responsive. We assign a utility of -1 to any set of students with cardinality exceeding $q_{f}$.

The cutoff of a college $f \in F$ is the minimal score $P^{f} \in[0,1]$ required for admission at college $f$. A student $w \in W$ can afford college $f$ if $P^{f} \leq u^{f}(\{(f, w)\})$, that is, college $f$ would accept student $w$. A student's demand given a vector of cutoffs is her favorite college among those she can afford or the empty set if no colleges are affordable. More formally, with $P=\left(P^{f}\right)_{f \in F}$ denoting the vector of cutoffs, we have

$$
d^{w}(P)=\arg \max _{\left\{\{(f, w)\} \in X^{w} \mid u^{f}(\{(f, w)\}) \geq P^{f}\right\}} u^{w}(\{(f, w)\}) .
$$

Because of the strictness of preferences, the set $d^{w}(P)$ is a singleton. Aggregate demand for college $f$ is equal to

$$
d_{f}(P)=\#\left\{w \in W \mid\{(f, w)\} \in d^{w}(P)\right\} .
$$

A market clearing cutoff $P$ is a vector of cutoffs that clears supply of and demand for colleges, i.e., for every $f \in F, d_{f}(P) \leq q_{f}$ and $d_{f}(P)=q_{f}$ if $P^{f}>0$. Azevedo and Leshno 
(2016) show how market clearing cutoffs are related to pairwise-stable outcomes in the model with a continuum of students and explain how to interpret the cutoffs as prices. The analysis of school choice in terms of market clearing cutoffs has also been shown to be very fruitful in Abdulkadiroğlu, Che, and Yasuda (2015), who use demand functions $d^{w}$ to pin down the matching of a continuum of students to a finite set of schools and to study the welfare properties of alternative ways to set priorities of the schools as a result of lotteries and messages by students.

How are the market clearing cutoffs related to expectational equilibria? Assume that $P^{*}$ is a market clearing cutoff. For every $w \in W$, define $R^{* w}$ as the set of colleges with a cutoff above the score of student $w$, so

$$
R^{* w}=\left\{\{(f, w)\} \in X^{w} \mid P^{f}>u^{f}(\{(f, w)\})\right\} .
$$

These are the colleges which are unaffordable for the student, so the student expects rationing for these colleges. It is easily verified that $d^{w}\left(P^{*}\right)=\delta^{w}\left(R^{* w}\right)$. An expectational equilibrium is obtained by defining

$$
\begin{aligned}
A^{*} & =\left\{(f, w) \in \bar{Y} \mid(f, w) \in \delta^{w}\left(R^{* w}\right)\right\}, \\
Q^{* f} & =\left\{(f, w) \in \bar{Y} \backslash A^{*} \mid P^{* f} \leq u^{f}(\{(f, w)\})\right\}, \quad f \in F,
\end{aligned}
$$

so the outcome $A^{*}$ corresponds simply to the set of college-student pairs as demanded by the students and $Q^{* f}$ is such that college $f$ expects rationing on all students with a score at least as high as the cutoff of college $f$ that do not demand college $f$.

Proposition 3.1: If $P^{*}$ is a market clearing cutoff, then $\left(A^{*}, Q^{*}, R^{*}\right)$ as defined in (3.1)-(3.3) is an expectational equilibrium.

Proof: To show that $\left(A^{*}, Q^{*}, R^{*}\right)$ is an expectational equilibrium, we verify the three conditions of Definition 2.6.

Consider a college $f \in F$. It holds that

$$
\begin{aligned}
\beta^{f}\left(Q^{* f}\right) & =\left\{A^{f} \in X^{f} \mid A^{f} \cap Q^{f}=\emptyset\right\} \\
& =\left\{A^{f} \in X^{f} \mid \forall y \in A^{f}, y \in A^{* f} \text { or } P^{* f}>u^{f}(\{y\})\right\} .
\end{aligned}
$$

If $d_{f}^{\mathrm{A}}\left(P^{*}\right)=q_{f}$, then $\# A^{* f}=q_{f}$, so $\delta^{f}\left(Q^{* f}\right)=A^{* f}$ since $A^{* f}$ consists of those $q_{f}$ students in the budget set of college $f$ with the highest scores and preferences of the college are responsive. If $d_{f}^{\mathrm{A}}\left(P^{*}\right)<q_{f}$, then it holds by the definition of a market clearing cutoff that $P^{* f}=0$, so $\beta^{f}\left(Q^{* f}\right)=\left\{A^{f} \in X^{f} \mid A^{f} \subset A^{* f}\right\}$ and $\delta^{f}\left(Q^{* f}\right)=A^{* f}$, where we use that college $f$ finds all students acceptable.

Clearly, by the definition of $A^{*}$, it holds that, for every $w \in W, A^{* w} \in \delta^{w}\left(R^{* w}\right)$.

Finally, we show that $Q^{*} \cap R^{*}=\emptyset$. Suppose $(f, w) \in Q^{*} \cap R^{*}$. Since $(f, w) \in Q^{* f}$, we have that $P^{* f} \leq u^{f}(\{(f, w)\})$. Since $(f, w) \in R^{* w}$, it holds that $P^{* f}>u^{f}(\{(f, w)\})$, so we 
obtain a contradiction. Consequently, we have that $Q^{*} \cap R^{*}=\emptyset$.

We also have the other direction. Let $\left(A^{*}, Q^{*}, R^{*}\right)$ be an expectational equilibrium. Now, for every $f \in F$, define the cutoff $P^{* f}$ by

$$
\begin{array}{ll}
P^{* f}=\min _{(f, w) \in A^{* f}} u^{f}(\{(f, w)\}), & \text { if } \# A^{* f}=q_{f}, \\
P^{* f}=0, & \text { otherwise, }
\end{array}
$$

so $P^{* f}$ is taken equal to the lowest score of a student that has been accepted by college $f$.

Proposition 3.2: If $\left(A^{*}, Q^{*}, R^{*}\right)$ is an expectational equilibrium, then $P^{*}$ as defined in (3.4)-(3.5) is a market clearing cutoff.

Proof: To show that $P^{*}=\left(P^{* f}\right)_{f \in F}$ is a market clearing cutoff, we have to argue that, for every $f \in F, d_{f}^{\mathrm{A}}\left(P^{*}\right) \leq q_{f}$ and $d_{f}^{\mathrm{A}}\left(P^{*}\right)=q_{f}$ if $P_{f}^{*}>0$. We achieve this by showing that $(f, w) \in A^{* w}$ if and only if $\{(f, w)\} \in d^{w}\left(P^{*}\right)$. The fact that the utility of a college $f \in F$ is equal to -1 if the cardinality of the set of students exceeds $q_{f}$, whereas $u^{f}(\emptyset)=0$, then implies $d_{f}^{\mathrm{A}}\left(P^{*}\right) \leq q_{f}$. It follows from (3.4) and (3.5) that $d_{f}^{\mathrm{A}}\left(P^{*}\right)=q_{f}$ if $P_{f}^{*}>0$.

Let $(f, w) \in A^{* w}$. It holds by (3.4) and (3.5) that $u^{f}(\{(f, w)\}) \geq P^{* f}$.

Suppose there is $f^{\prime} \in F$ such that $u^{f^{\prime}}\left(\left\{\left(f^{\prime}, w\right)\right\}\right) \geq P^{* f^{\prime}}$ and $u^{w}\left(\left\{\left(f^{\prime}, w\right)\right\}\right)>u^{w}(\{(f, w)\})$. Since $A^{* w} \in \delta^{w}\left(R^{* w}\right)$ it follows that $\left(f^{\prime}, w\right) \in R^{* w}$. By Condition 3 of Definition 2.6, it follows that $\left(f^{\prime}, w\right) \notin Q^{* f^{\prime}}$. From $\left(f^{\prime}, w\right) \notin A^{* f^{\prime}}$, we have that $u^{f^{\prime}}\left(\left\{\left(f^{\prime}, w\right)\right\}\right)<P^{* f^{\prime}}$, leading to a contradiction. Consequently, for every $f^{\prime} \in F$, it holds that $u^{f^{\prime}}\left(\left\{\left(f^{\prime}, w\right)\right\}\right)<P^{* f^{\prime}}$ or $u^{w}\left(\left\{\left(f^{\prime}, w\right)\right\}\right) \leq u^{w}(\{(f, w)\})$. It follows that $\{(f, w)\} \in d^{w}\left(P^{*}\right)$.

Let $w \in W$ be such that $A^{* w}=\emptyset$. It holds that $\emptyset \in \delta^{w}\left(R^{* w}\right)$. For every $f \in F$, by the assumption that $u^{w}(\{(f, w)\})>0$, it follows that $(f, w) \in R^{* w}$, so by Condition 3 of Definition $2.6(f, w) \notin Q^{* f}$. From $A^{* w}=\emptyset$, it follows that, for every $f \in F,(f, w)$ is not part of the set in $\delta^{f}\left(Q^{* f}\right)$, so $u^{f}(\{(f, w)\})<P^{* f}$. It follows that $d^{w}\left(P^{*}\right)=\emptyset$.

We have shown the equivalence between an expectational equilibrium and a market clearing cutoff in a model of school choice. Our notion of expectational equilibrium is defined for a much wider class of models, allowing for a potentially uncountable set of contracts and completely general preferences.

\section{Equivalence between Expectational Equilibria and Stable Outcomes}

In this section, we show that an outcome $A^{*}$ is part of some expectational equilibrium if and only if it is a stable outcome. We first give the definition of a stable outcome. 
The choice correspondence $C^{i}$ of agent $i \in I$ is defined by

$$
C^{i}(Y)=\arg \max _{\left\{A^{i} \in X^{i} \mid A^{i} \subset Y^{i}\right\}} u^{i}\left(A^{i}\right), \quad Y \subset \bar{Y} .
$$

The set $C^{i}(Y)$ consists of all sets of contracts in $Y^{i}$ that maximize the utility of agent $i$.

As defined in Hatfield, Kominers, Nichifor, Ostrovsky, and Westkamp (2013), an outcome is stable if it is individually rational and there is no blocking set of contracts.

Definition 4.1: An outcome $A \in \mathcal{A}$ of the economy $\mathcal{E}=\left(\bar{Y},\left(u^{i}\right)_{i \in I}\right)$ is stable if:

1. For every $i \in I, A^{i} \in C^{i}(A)$.

2. There is no non-empty $B \subset \bar{Y} \backslash A$ such that for every $i \in I(B)$, for every $Y^{i} \in$ $C^{i}(A \cup B)$, it holds that $B^{i} \subset Y^{i}$.

Condition 1 of Definition 4.1 corresponds to individual rationality. Each worker $w \in W$ is weakly better off signing the contract in $A^{w}$ than not signing it in case $A^{w}$ is non-empty. Each firm $f \in F$ is weakly better off keeping all the contracts in $A^{f}$ than canceling some of them.

The requirement $B^{i} \subset Y^{i}$ for every $Y^{i} \in C^{i}(A \cup B)$ in Condition 2 implies that the blocking set $B$ contains a single contract for each worker $w \in w(B)$. Moreover, that contract is strictly preferred to $A^{w}$ by worker $w$. All firms $f \in f(B)$ are strictly better off by signing all the contracts in $B^{f}$ and potentially keeping some of the contracts in $A^{f}$ than by sticking to the contracts in $A^{f}$. A firm may have multiple optimal choices regarding the contracts in $A^{f}$ it wants to keep. It is straightforward to verify that for every firm $f \in f(B)$ involved in blocking set $B, B^{f}$ is a blocking set as well.

The concepts of expectational equilibrium and stable outcomes cannot be directly compared. An expectational equilibrium provides more information as it also specifies rationing constraints, i.e., expectations regarding the impossibility to trade particular contracts. We therefore focus on the set of outcomes that can be supported by an expectational equilibrium and compare them to the set of stable outcomes. The set of outcomes $\mathcal{A}^{\text {ee }}$ that can be supported by an expectational equilibrium of an economy $\mathcal{E}$ is defined as

$$
\mathcal{A}^{\text {ee }}=\left\{A \in \mathcal{A} \mid \exists(Q, R) \in 2^{\bar{Y}} \times 2^{\bar{Y}} \text { such that }(A, Q, R) \text { is an expectational equilibrium }\right\} \text {. }
$$

The set of all stable outcomes is denoted by $\mathcal{A}^{\text {so }}$.

The next result shows that every stable outcome is supported by an expectational equilibrium. More precisely, given an outcome $A \in \mathcal{A}$, define $Q(A) \subset \bar{Y}$ and $R(A) \subset \bar{Y}$ by

$$
\begin{aligned}
Q(A) & =\left\{y \in \bar{Y} \backslash A \mid u^{w(y)}(\{y\}) \leq u^{w(y)}(A)\right\} \\
R(A) & =\bar{Y} \backslash(A \cup Q(A)) .
\end{aligned}
$$


The set $Q(A)$ consists of those contracts which provide the worker with a utility less than or equal to the utility of $A$. These are contracts for which the firms do not expect trade with the workers. The set $R(A)$ consists of all contracts outside $A$ and $Q(A)$. We show that if $A^{*}$ is a stable outcome, then $\left(A^{*}, Q\left(A^{*}\right), R\left(A^{*}\right)\right)$ is an expectational equilibrium.

Theorem 4.2: Consider an economy $\mathcal{E}=\left(\bar{Y},\left(u^{i}\right)_{i \in I}\right)$. If $A^{*} \in \mathcal{A}^{\mathrm{so}}$, then $\left(A^{*}, Q\left(A^{*}\right), R\left(A^{*}\right)\right)$ is an expectational equilibrium, so $\mathcal{A}^{\text {so }} \subset \mathcal{A}^{\mathrm{ee}}$.

Proof: Let $A^{*} \in \mathcal{A}^{\text {so }}$. Define $Q^{*}=Q\left(A^{*}\right)$ and $R^{*}=R\left(A^{*}\right)$. We show first that, for every $f \in F, A^{* f} \in \delta^{f}\left(Q^{* f}\right)$.

Suppose there is $f \in F$ and $A^{f} \in \beta^{f}\left(Q^{* f}\right)$ such that $u^{f}\left(A^{f}\right)>u^{f}\left(A^{* f}\right)$. Since $A^{f} \cap Q^{* f}=$ $\emptyset$, it holds by definition of $Q^{*}=Q\left(A^{*}\right)$ that, for every $y \in A^{f} \backslash A^{* f}, u^{w(y)}(\{y\})>u^{w(y)}\left(A^{*}\right)$.

Let $Y^{* f} \in C^{f}\left(A^{f} \cup A^{*}\right)$ be an element in $C^{f}\left(A^{f} \cup A^{*}\right)$ such that $Y^{* f} \backslash A^{* f}$ is minimal, i.e., there is no $Y^{f} \in C^{f}\left(A^{f} \cup A^{*}\right)$ such that $Y^{f} \backslash A^{* f}$ is a proper subset of $Y^{* f} \backslash A^{* f}$. Since $A^{f} \cap A^{*}$ is finite, such a minimal element exists. It holds that

$$
u^{f}\left(Y^{* f}\right) \geq u^{f}\left(A^{f}\right)>u^{f}\left(A^{* f}\right) .
$$

Suppose $Y^{* f} \subset A^{* f}$. Then $A^{* f} \notin C^{f}\left(A^{*}\right)$, so Condition 1 of Definition 4.1 is violated, and we obtain a contradiction to the stability of $A^{*}$. Consequently, $Y^{* f} \backslash A^{* f}$ is a non-empty subset of $A^{f} \backslash A^{* f}$.

We define $B=Y^{* f} \backslash A^{* f}$ and we use the minimality of $Y^{* f} \backslash A^{* f}$ to conclude that for every $Y^{f} \in C^{f}\left(A^{*} \cup B\right)$ it holds that $B=B^{f} \subset Y^{f}$. Since $Y^{* f} \subset A^{f} \cup A^{*}$, it holds that $Y^{* f} \cap Q^{* f}=$ $\emptyset$, so by the definition of $Q\left(A^{*}\right)$ we have for every $y \in B$ that $u^{w(y)}(\{y\})>u^{w(y)}\left(A^{*}\right)$. We conclude that for every $w \in w(B), C^{w}\left(A^{*} \cup B\right)=\left\{B^{w}\right\}$. Therefore $B$ is a blocking set of contracts, Condition 2 of Definition 4.1 is violated, and we obtain a contradiction to the stability of $A^{*}$. Consequently, it holds for every $f \in F$ that $A^{* f} \in \delta^{f}\left(Q^{* f}\right)$.

We show next that, for every $w \in W, A^{* w} \in \delta^{w}\left(R^{* w}\right)$.

Suppose there is $w \in W$ and $A^{w} \in \beta^{w}\left(R^{* w}\right)$ such that $u^{w}\left(A^{w}\right)>u^{w}\left(A^{* w}\right)$. Since $A^{w} \cap R^{* w}=\emptyset$ and $A^{w} \neq A^{* w}$, we have $A^{w} \subset Q^{* w}$ and therefore, by the definition of $R\left(A^{*}\right)$, $u^{w}\left(A^{w}\right) \leq u^{w}\left(A^{*}\right)=u^{w}\left(A^{* w}\right)$, a contradiction. Consequently, it holds for every $w \in W$ that $A^{* w} \in \delta^{w}\left(R^{* w}\right)$.

By construction, it holds that $Q^{*} \cap R^{*}=\emptyset$.

We conclude that $\left(A^{*}, Q^{*}, R^{*}\right)$ is an expectational equilibrium of the economy $\mathcal{E}$.

The proof of Theorem 4.2 relies on the construction of particular rationing constraints $Q\left(A^{*}\right)$ and $R\left(A^{*}\right)$, which may not be unique in supporting a particular stable outcome $A^{*}$. Nevertheless, the next result shows the converse of Theorem 4.2. If $\left(A^{*}, Q^{*}, R^{*}\right)$ is an expectational equilibrium of the economy $\mathcal{E}$, then $A^{*}$ is a stable outcome. 
TheOREM 4.3: Consider an economy $\mathcal{E}=\left(\bar{Y},\left(u^{i}\right)_{i \in I}\right)$. If $\left(A^{*}, Q^{*}, R^{*}\right) \in \mathcal{A} \times 2^{\bar{Y}} \times 2^{\bar{Y}}$ is an expectational equilibrium of $\mathcal{E}$, then $A^{*}$ is a stable outcome, so $\mathcal{A}^{\text {ee }} \subset \mathcal{A}^{\text {so }}$.

Proof: Let $\left(A^{*}, Q^{*}, R^{*}\right) \in \mathcal{A} \times 2^{\bar{Y}} \times 2^{\bar{Y}}$ be an expectational equilibrium of $\mathcal{E}$. Suppose $A^{*}$ is not a stable outcome. Then there is $i \in I$ such that $A^{* i} \notin C^{i}\left(A^{*}\right)$ or there is a non-empty $B \subset \bar{Y} \backslash A^{*}$ such that for every $i \in I(B)$, for every $Y^{i} \in C^{i}\left(A^{*} \cup B\right)$, it holds that $B^{i} \subset Y^{i}$.

In the first case, take $A^{i} \in C^{i}\left(A^{*}\right)$. If $i \in F$, then $A^{i} \subset A^{* i}$ implies $A^{i} \in \beta^{i}\left(Q^{* i}\right)$, so $A^{* i} \notin \delta^{i}\left(Q^{* i}\right)$, a contradiction to Condition 1 of Definition 2.6. If $i \in W$, then $A^{i} \subset A^{* i}$ implies $A^{i} \in \beta^{i}\left(R^{*}\right)$, so $A^{* i} \notin \delta^{i}\left(R^{* i}\right)$, a contradiction to Condition 2 of Definition 2.6.

In the second case, for every $w \in w(B)$ it holds that $u^{w}\left(B^{w}\right)>u^{w}\left(A^{* w}\right)$, so it follows from $A^{* w} \in \delta^{w}\left(R^{* w}\right)$ that $B^{w} \subset R^{*}$, so by Condition 3 of Definition 2.6 it holds that $B^{w} \cap Q^{*}=\emptyset$. Thus we have $B \cap Q^{*}=\emptyset$. Take some $f \in f(B)$ and some $Y^{f} \in C^{f}\left(A^{*} \cup B\right)$. It holds that $u^{f}\left(Y^{f}\right)>u^{f}\left(A^{*}\right)$ and, since $A^{*} \cap Q^{*}=\emptyset$ and $B \cap Q^{*}=\emptyset$, it holds that $Y^{f} \in \beta^{f}\left(Q^{* f}\right)$, so $A^{* f} \notin \delta^{f}\left(Q^{* f}\right)$, a contradiction to Condition 1 of Definition 2.6.

Consequently, $A^{*}$ is a stable outcome.

Combining the results of Theorems 4.2 and 4.3 leads to the following corollary.

Corollary 4.4: Consider an economy $\mathcal{E}=\left(\bar{Y},\left(u^{i}\right)_{i \in I}\right)$. It holds that $\mathcal{A}^{\text {so }}=\mathcal{A}^{\mathrm{ee}}$.

The matching concept of stability and the equilibrium concept of expectational equilibrium lead to exactly the same conclusions. The equivalence holds for infinite sets of contracts and for completely general preferences. Preferences are not required to be strict or to satisfy substitutability assumptions and may in fact exhibit discontinuities.

It is remarkable that expectional equilibrium singles out stability as the relevant concept from matching theory. Other concepts that are frequently used in matching theory are pairwise stability, the core, and the strong core. Shapley and Shubik (1971), Crawford and Knoer (1981), Kelso and Crawford (1982), and Roth (1984) have shown that in two-sided matching environments with substitutable preferences competitive equilibrium is equivalent to pairwise stability, which under these circumstances is equivalent to stability. However, under our general conditions, the concepts of pairwise stability, the core, and the strong core lead to different predictions than stability. The notion of pairwise stability was introduced in Gale and Shapley (1962). In our notation, it is defined as follows.

Definition 4.5: An outcome $A \in \mathcal{A}$ of the economy $\mathcal{E}=\left(\bar{Y},\left(u^{i}\right)_{i \in I}\right)$ is pairwise stable if:

1. For every $i \in I, A^{i} \in C^{i}(A)$. 
2. There is no singleton $B \subset \bar{Y} \backslash A$ such that for every $i \in I(B)$, for every $Y^{i} \in C^{i}(A \cup B)$, it holds that $B^{i} \subset Y^{i}$.

Condition 1 of Definition 4.5 is the requirement of individual rationality. No agent will stick to a set of contracts if it is better not to sign any of them. Condition 2 of Definition 4.5 requires that no pair of agents can sign a contract which, together with a suitable selection of the existing contracts in $A$, gives both a strictly higher utility.

EXAmple 4.6: Consider a firm $f$ and two workers $w_{1}$ and $w_{2}$. Contracts are completely standardized, resulting in the set $\bar{Y}=\left\{\left(f, w_{1}\right),\left(f, w_{2}\right)\right\}$ of possible contracts. The utility function of the firm is specified by

$$
\begin{aligned}
u^{f}(\emptyset) & =0, \\
u^{f}\left(\left\{\left(f, w_{1}\right)\right\}\right) & =0, \\
u^{f}\left(\left\{\left(f, w_{2}\right)\right\}\right) & =0, \\
u^{f}\left(\left\{\left(f, w_{1}\right),\left(f, w_{2}\right)\right\}\right) & =1 .
\end{aligned}
$$

The utility function of worker $w_{1}$ is given by

$$
\begin{aligned}
u^{w_{1}}(\emptyset) & =0, \\
u^{w_{1}}\left(\left\{\left(f, w_{1}\right)\right\}\right) & =1,
\end{aligned}
$$

and of worker $w_{2}$ by

$$
\begin{aligned}
u^{w_{2}}(\emptyset) & =0, \\
u^{w_{2}}\left(\left\{\left(f, w_{2}\right)\right\}\right) & =1 .
\end{aligned}
$$

The firm strictly prefers hiring both workers to hiring a single worker or no worker and is indifferent between all options different from hiring both workers. Each worker prefers to sign the contract to not signing it. The only stable outcome is $A=\left\{\left(f, w_{1}\right),\left(f, w_{2}\right)\right\}$ and $(A, Q, R)$ with $Q=R=\emptyset$ is an expectational equilibrium.

Consider now the outcome $A^{\prime}=\emptyset$. It is clearly individually rational and it is impossible to find a singleton $B$ as in Condition 2 of Definition 4.5 since the firm will not get a positive utility when signing a contract with a single worker. We find that $A^{\prime}$ is pairwise stable. The outcome $A^{\prime}=\emptyset$ is not stable against general deviations $B$. In particular, it is not stable against a deviation involving contracts with both workers. By Corollary 4.4 it follows that $A^{\prime}$ cannot be supported as an expectational equilibrium. A direct argument is as follows. The firm will demand both contracts, unless $\left(f, w_{1}\right) \in Q$ or $\left(f, w_{2}\right) \in Q$. Without loss of generality, suppose $\left(f, w_{1}\right) \in Q$. Then $\left(f, w_{1}\right) \notin R$ by Condition 3 of Definition 2.6, so worker $w_{1}$ will demand the contract $\left(f, w_{1}\right)$, a contradiction since $A^{\prime}$ does not contain a contract involving worker $w_{1}$. 
The core is defined as follows.

Definition 4.7: An outcome $A \in \mathcal{A}$ of the economy $\mathcal{E}=\left(\bar{Y},\left(u^{i}\right)_{i \in I}\right)$ belongs to the core if, for every coalition $S \subset I$, there is no outcome $B \in \mathcal{A}$ such that $I(B)=S$ and for every $i \in S, u^{i}\left(B^{i}\right)>u^{i}\left(A^{i}\right)$.

An outcome belongs to the core if there is no blocking coalition $S$ that can sign contracts among its members $S$ only and strictly improve the utility of every coalition member. The next example shows that a core outcome does not need to be stable.

EXAMPLE 4.8: We consider the primitives of Example 4.6, so the only stable outcome is $A=\left\{\left(f, w_{1}\right),\left(f, w_{2}\right)\right\}$. The outcome $A$ belongs to the core. The outcomes $A^{\prime}=\left\{\left(f, w_{1}\right)\right\}$ and $A^{\prime \prime}=\left\{\left(f, w_{2}\right)\right\}$ are both core elements as well. Indeed, the only way to improve the utility of the firm is by $A=\left\{\left(f, w_{1}\right),\left(f, w_{2}\right)\right\}$, but that leaves $w_{1}$ indifferent compared to $A^{\prime}$ and $w_{2}$ indifferent compared to $A^{\prime \prime}$.

We next turn to the concept of the strong core.

Definition 4.9: An outcome $A \in \mathcal{A}$ of the economy $\mathcal{E}=\left(\bar{Y},\left(u^{i}\right)_{i \in I}\right)$ belongs to the strong core if, for every coalition $S \subset I$, there is no outcome $B \in \mathcal{A}$ such that $I(B)=S$, for every $i \in S, u^{i}\left(B^{i}\right) \geq u^{i}\left(A^{i}\right)$, and, for some $i \in S, u^{i}\left(B^{i}\right)>u^{i}\left(A^{i}\right)$.

An outcome belongs to the strong core if there is no coalition $S$ that can sign contracts as to make all its members weakly better off and at least one member strictly better off. The next example shows that a stable outcome may not belong to the strong core.

ExAmple 4.10: We consider the primitives of Example 4.6, but make the firm indifferent between hiring one or two workers by setting

$$
u^{f}\left(\left\{\left(f, w_{1}\right),\left(f, w_{2}\right)\right\}\right)=0 .
$$

The outcomes $A=\left\{\left(f, w_{1}\right),\left(f, w_{2}\right)\right\}, A^{\prime}=\left\{\left(f, w_{1}\right)\right\}, A^{\prime \prime}=\left\{\left(f, w_{2}\right)\right\}$, and $A^{\prime \prime \prime}=\emptyset$ are all stable, since it is impossible to make the firm strictly better off. The outcomes $A^{\prime}, A^{\prime \prime}$, and $A^{\prime \prime \prime}$ do not belong to the strong core. Coalition $\left\{f, w_{1}, w_{2}\right\}$ can block these outcomes by outcome $A$, since this leaves the firm indifferent and makes at least one of the workers $w_{1}$ and $w_{2}$ strictly better off. 


\section{Existence of Expectational Equilibria}

In this section, we give conditions such that an expectational equilibrium exists. The main condition is that the preferences of firms need to satisfy substitutability. In the model of Example 2.4, substitutable preferences were introduced by Kelso and Crawford (1982) in terms of changes in an agent's demand as prices change. Roth (1984) introduced a related choice-theoretic definition under which substitutability is expressed in terms of changes in an agent's choice as the set of available options changes. We follow the latter approach here. For the relationships between the various notions of substitutes that have been introduced in the literature, we refer the reader to Hatfield, Kominers, Nichifor, Ostrovsky, and Westkamp (2019).

Definition 5.1: The preferences of firm $f \in F$ in the economy $\mathcal{E}=\left(\bar{Y},\left(u^{i}\right)_{i \in I}\right)$ are substitutable if, for every finite $Y, Y^{\prime} \subset \bar{Y}$ such that $Y \subset Y^{\prime}$, for every $A^{f} \in C^{f}(Y)$, there is some $A^{\prime f} \in C^{f}\left(Y^{\prime}\right)$ such that $\left(A^{\prime f} \cap Y\right) \subset A^{f}$.

If $A^{f}$ is an optimal choice for firm $f$ within the set of contracts $Y$, and the set of contracts out of which the firm can choose expands to $Y^{\prime}$, then the firm has an optimal choice $A^{\prime f}$ which does not involve contracts in $Y$ that are outside $A^{f}$.

In a set-up without contracts, Sotomayor (1999) extends the definition of Roth (1984) to the case where indifferences are allowed and requires an analogue of Definition 5.1 as well as a related condition in case the set of available choices is reduced. For existence, it suffices to require only one out of the two conditions.

Although our set $\bar{Y}$ is allowed to be uncountable, Definition 5.1 only involves comparisons between the choice behavior out of finite sets $Y$ and $Y^{\prime}$. Aziz, Brill, and Harrenstein (2013) show for the case where $\bar{Y}$ is finite that testing substitutability of weak preferences can be performed in polynomial time.

We now define an adjustment process to find a stable outcome in case the set $\bar{Y}$ is finite. We then use a limit argument to show the existence of a stable outcome, and by Corollary 4.4 the existence of an expectional equilibrium, in the general case.

Definition 5.2: (Adjustment process for a finite set $\bar{Y}$ )

SteP 1. Let $k=0$. The set of permitted contracts $Y_{k}$ is equal to $\bar{Y}$ and the set of tentatively accepted contracts $A_{k}$ is equal to $\emptyset$.

STEP 2. Every worker $w \in W \backslash w\left(A_{k}\right)$ proposes an arbitrarily chosen element of $C^{w}\left(Y_{k}\right)$. Let $Z_{k+1}$ be the union of the set of contracts as proposed by $w \in W \backslash w\left(A_{k}\right)$ and the set $A_{k}$.

SteP 3. Every firm $f \in f\left(Z_{k+1}\right)$ tentatively accepts one arbitrarily chosen element 
of $C^{f}\left(Z_{k+1}\right)$. Let $A_{k+1}$ be the union of the tentatively accepted elements by the firms in $f\left(Z_{k+1}\right)$.

STEP 4. The process stops if $A_{k+1}=Z_{k+1}$. In that case the contracts in $A_{k+1}$ are permanently accepted. Otherwise, we define $Y_{k+1}=Y_{k} \backslash\left(Z_{k+1} \backslash A_{k+1}\right)$. Increase the value of $k$ by 1 and return to Step 2 .

The adjustment process is initiated in Step 1 by setting $k$ equal to 0 , considering all contracts in $Y_{k}$ as permitted, and having no tentatively accepted contracts. In Step 2 every worker without a contract proposes one of his best contracts within the set of permitted contracts $Y_{k}$. Together with the tentatively accepted contracts $A_{k}$ these contracts are collected in the set $Z_{k+1}$ out of which the firms tentatively choose an optimal set of contracts in Step 3. The sets of tentatively accepted contracts are collected in the set $A_{k+1}$. If all contracts in $Z_{k+1}$ were accepted, then the process stops in Step 4 with set of permanently accepted contracts $A_{k+1}$. Otherwise, the set $Z_{k+1} \backslash A_{k+1}$ is non-empty and these contracts are removed from $Y_{k}$, resulting in the set $Y_{k+1}$. The value of $k$ is increased by 1 and the process returns to Step 2.

Firms choose from the set of contracts $Z_{k+1}$ in Step 3 of the adjustment process. The next lemma implies that when a firm has substitutable preferences, then it cannot improve its utility by making a choice out of the set of contracts $\cup_{j=1}^{k+1} Z_{j}$.

Lemma 5.3: Consider an economy $\mathcal{E}=\left(\bar{Y},\left(u^{i}\right)_{i \in I}\right)$ where $\bar{Y}$ is finite and let $\left(Z_{j}, A_{j}\right)$ for $j=1, \ldots, k$, be the sets generated in the first $k$ iterations of the adjustment process in Definition 5.2. Let $f$ be a firm with substitutable preferences. Then $A_{k}^{f} \in C^{f}\left(\cup_{j=1}^{k} Z_{j}\right)$.

Proof: Assume $k=1$. If $f \notin f\left(Z_{1}\right)$, then it holds that $A_{1}^{f}=\emptyset$ and $C^{f}\left(Z_{1}\right)=\{\emptyset\}$. If $f \in f\left(Z_{1}\right)$, then we have $A_{1}^{f} \in C^{f}\left(Z_{1}\right)$.

Assume the lemma has been shown for some $k \in \mathbb{N}$. We show it to hold for $k+1$.

If $f \notin f\left(Z_{k+1}\right)$, then we have $A_{k+1}^{f}=\emptyset$. Since $A_{k} \subset Z_{k+1}$, it holds that $f \notin f\left(A_{k}\right)$, so it follows from the induction hypothesis that $A_{k}^{f}=\emptyset \in C^{f}\left(\cup_{j=1}^{k} Z_{j}\right)$. Since $f \notin f\left(Z_{k+1}\right)$, we have $C^{f}\left(\cup_{j=1}^{k+1} Z_{j}\right)=C^{f}\left(\cup_{j=1}^{k} Z_{j}\right)$, so $A_{k+1}^{f}=\emptyset \in C^{f}\left(\cup_{j=1}^{k+1} Z_{j}\right)$. Next consider the case where $f \in f\left(Z_{k+1}\right)$. It holds by the induction hypothesis that $A_{k}^{f} \in C^{f}\left(\cup_{j=1}^{k} Z_{j}\right)$. By the definition of substitutable preferences, there is $A^{\prime f} \in C^{f}\left(\cup_{j=1}^{k+1} Z_{k+1}\right)$ such that $\left(A^{\prime f} \cap \cup_{j=1}^{k} Z_{j}\right) \subset A_{k}^{f}$. Since $A_{k}^{f} \subset Z_{k+1}$, it follows that $A^{\prime f} \subset Z_{k+1}$, so $A^{\prime f} \in C^{f}\left(Z_{k+1}\right)$. It follows that $A_{k+1}^{f} \in C^{f}\left(\cup_{j=1}^{k+1} Z_{j}\right)$.

TheOREM 5.4: Consider an economy $\mathcal{E}=\left(\bar{Y},\left(u^{i}\right)_{i \in I}\right)$ where $\bar{Y}$ is finite and all firms have substitutable preferences. The adjustment process of Definition 5.2 terminates in a finite number of steps with a set $A$ of permanently accepted contracts. The set $A$ is a stable 
outcome.

ProOF: Suppose the adjustment process does not terminate in a finite number of steps with a set $A$ of permanently accepted contracts. Then, for every $k \in \mathbb{N}$, the set $Z_{k+1} \backslash A_{k+1}$ is non-empty in Step 4 and the cardinality of the set $Y_{k+1}$ is at least one less than the cardinality of the set $Y_{k}$. Since the set $Y_{0}$ is equal to $\bar{Y}$, so has finitely many elements, this leads to a contradiction. Consequently, the process terminates after a finite number of iterations $k \in \mathbb{N}$ with a set $A=A_{k}$ of permanently accepted contracts.

Since by Step 2 every worker is involved in at most one contract in $A$ and by Step 3, for every firm $f \in f(A), A^{f} \in X^{f}$, it follows that $A$ is an outcome.

Every element of $A$ has been proposed by a worker in Step 2. It follows that, for every $w \in w(A), u^{w}(A) \geq u^{w}(\emptyset)$. For every $w \in W \backslash w(A)$, it holds that $A^{w}=\emptyset$. In both cases it holds that $A^{w} \in C^{w}(A)$.

For every $f \in f(A)$, it holds by Step 3 that $A^{f} \in C^{f}(A)$. For every $f \in F \backslash f(A)$, it holds that $A^{f}=\emptyset$, so trivially $A^{f} \in C^{f}(A)$.

Condition 1 of Definition 4.1 is therefore satisfied by the outcome $A$.

Suppose there is a non-empty $B \subset \bar{Y} \backslash A$ such that for every $i \in I(B)$, for every $Y^{i} \in C^{i}(A \cup B)$, it holds that $B^{i} \subset Y^{i}$. We have that $f(B) \neq \emptyset$. Let $f \in f(B)$. Then $B^{f}$ is a blocking set of contracts as well. For every $w \in w\left(B^{f}\right)$ it holds that $u^{w}\left(B^{w}\right)>u^{w}\left(A^{w}\right)$. For every $w \in w\left(B^{f}\right)$, at some iteration of the adjustment process, $B^{w}$ has been rejected in Step 3 by firm $f$, so $B \subset \cup_{j=1}^{k} Z_{j}$. Since by Lemma $5.3 A^{f} \in C^{f}\left(\cup_{j=1}^{k} Z_{j}\right)$ and $A \cup B \subset \cup_{j=1}^{k} Z_{j}$, we have $A^{f} \in C^{f}(A \cup B)$. Since $B \subset \bar{Y} \backslash A, A^{f}$ does not contain $B^{f}$, contradicting our supposition. Consequently, there is no blocking set $B$ and Condition 2 of Definition 4.1 is satisfied by the set $A$.

To show existence of an expectational equilibrium in the general case, we assume that $\bar{Y}$ is a metric space with metric $d: \bar{Y} \times \bar{Y} \rightarrow \mathbb{R}$. For every $y \in \bar{Y}$, for every $\varepsilon>0$, we define the open $\varepsilon$ ball around $y$ by $B_{\varepsilon}(y)=\left\{y^{\prime} \in \bar{Y} \mid d\left(y^{\prime}, y\right)<\varepsilon\right\}$.

The set of contracts that are acceptable for a worker $w \in W$ is given by

$$
\bar{Y}_{+}^{w}=\left\{y \in \bar{Y}^{w} \mid u^{w}(\{y\}) \geq u^{w}(\emptyset)\right\}
$$

The collection of sets of contracts that are acceptable for a firm $f \in F$ and that consist entirely of contracts that are acceptable for the workers is given by

$$
X_{+}^{f}=\left\{Y^{f} \in X^{f} \mid Y^{f} \subset \cup_{w \in W} \bar{Y}_{+}^{w} \text { and } u^{f}\left(Y^{f}\right) \geq u^{f}(\emptyset)\right\} .
$$

For every $f \in F$, for every $w \in W$, the set of contracts that could be signed between $f$ and $w$ as part of a set of contracts in $X_{+}^{f}$ is given by

$$
\bar{Y}_{+}^{f w}=\left\{y \in \bar{Y}_{+}^{w} \mid \exists Y^{f} \in X_{+}^{f} \text { such that } y \in Y^{f}\right\} .
$$


For our existence result, we will assume the sets $\bar{Y}_{+}^{f w}$ to be compact and utility functions of firms and workers to be continuous.

TheOREM 5.5: Consider an economy $\mathcal{E}=\left(\bar{Y},\left(u^{i}\right)_{i \in I}\right)$ where $\bar{Y}$ is a metric space, for every $f \in F$, for every $w \in W, \bar{Y}_{+}^{f w}$ is compact, $u^{f}$ and $u^{w}$ are continuous, and all firms have substitutable preferences. Then the economy $\mathcal{E}$ has an expectational equilibrium.

Proof: As a consequence of Corollary 4.4, it is sufficient to show that $\mathcal{E}$ has a stable outcome. To do so, for every $f \in F$, for every $w \in W$, we approximate the set $\bar{Y}_{+}^{f w}$ by a finite set of contracts. Let some $f \in F, w \in W$, and $\varepsilon>0$ be given. Consider the open cover $\left\{B_{\varepsilon}(y) \mid y \in \bar{Y}_{+}^{f w}\right\}$ of $\bar{Y}_{+}^{f w}$. Since every set $\bar{Y}_{+}^{f w}$ is compact, the open cover $\left\{B_{\varepsilon}(y) \mid y \in \bar{Y}_{+}^{f w}\right\}$ has a finite subcover $\left\{B_{\varepsilon}(y) \mid y \in \widetilde{Y}^{f w}\right\}$, where $\widetilde{Y}^{f w}$ is a finite set of contracts in $\bar{Y}_{+}^{f w}$. We apply the adjustment process of Definition 5.2 to the finite set of contracts $\widetilde{Y}=\cup_{f \in F} \cup_{w \in W} \widetilde{Y}^{f w}$. By Theorem 5.4, the adjustment process terminates with a stable outcome $A$ of the economy $\mathcal{E}=\left(\widetilde{Y},\left(u^{i}\right)_{i \in I}\right)$.

Consider a sequence $\left(\varepsilon_{n}\right)_{n \in \mathbb{N}}$ of positive real numbers that converges to 0. For every $n \in \mathbb{N}$, let $\widetilde{Y}_{n}$ be a finite set of contracts as defined in the previous paragraph, and let $A_{n}$ be the resulting stable outcome of the economy $\mathcal{E}_{n}=\left(\widetilde{Y}_{n},\left(u^{i}\right)_{i \in I}\right)$. By listing the, potentially empty, contracts of the workers, we can represent every $A_{n}$ as an element of the set

$$
\prod_{w \in W}\left(\cup_{f \in F} \bar{Y}_{+}^{f w} \cup\{\emptyset\}\right) .
$$

Since the set $F$ is finite, we can assume without loss of generality that, for every $w \in W$, there exists $f \in F$ such that either, for every $n \in \mathbb{N}, \emptyset \neq A_{n}^{w} \subset \bar{Y}^{f}$ or, for every $n \in \mathbb{N}$, $A_{n}^{w}=\emptyset$. Since the set $\prod_{w \in W}\left(\cup_{f \in F} \bar{Y}_{+}^{f w} \cup\{\emptyset\}\right)$ is compact, the sequence $\left(A_{n}\right)_{n \in \mathbb{N}}$ has a convergent subsequence, with limit, say $A$. The remainder of the proof verifies that $A$ is a stable outcome of the economy $\mathcal{E}=\left(\bar{Y},\left(u^{i}\right)_{i \in I}\right)$.

It clearly holds that $A$ is an outcome. For every worker $w \in W$, it holds by continuity that $u^{w}(A) \geq u^{w}(\emptyset)$. For every $n \in \mathbb{N}, A_{n}$ is a stable outcome of the economy $\mathcal{E}_{n}=$ $\left(\widetilde{Y}_{n},\left(u^{i}\right)_{i \in I}\right)$, so by Condition 1 of Definition 4.1, for every $f \in F, A_{n}^{f} \in C^{f}\left(A_{n}\right)$, and we have by continuity of $u^{f}$ that $A^{f} \in C^{f}(A)$. We have shown that $A$ satisfies Condition 1 of Definition 4.1.

Suppose there is a non-empty $B \subset \bar{Y} \backslash A$ such that for every $i \in I(B)$, for every $Y^{i} \in C^{i}(A \cup B)$, it holds that $B^{i} \subset Y^{i}$. We have that $f(B) \neq \emptyset$. Let $f \in f(B)$ and let $Y^{f} \in C^{f}(A \cup B)$. Then $B^{f}$ is a blocking set of contracts as well. For every $w \in w\left(B^{f}\right)$ it holds that $u^{w}\left(B^{w}\right)>u^{w}\left(A^{w}\right)$. Moreover, it holds that $u^{f}\left(Y^{f}\right)>u^{f}\left(A^{f}\right)$. By continuity of $u^{f}$, every $y \in Y^{f}$ belongs to $\bar{Y}_{+}^{f w(y)}$.

For every $n \in \mathbb{N}$, for every $y \in B^{f}$, let $\widetilde{a}_{n}(y) \in \widetilde{Y}_{n}^{f w(y)}$ be such that $d\left(\widetilde{a}_{n}(y), y\right)<\varepsilon_{n}$ and define $\widetilde{A}_{n}=\left\{\widetilde{a}_{n}(y) \mid y \in B^{f}\right\} \cup \cup_{w \in w\left(Y^{f} \backslash B^{f}\right)} A_{n}^{w}$. It holds that $\lim _{n \rightarrow \infty} \widetilde{A}_{n}^{f}=Y^{f}$. By 
continuity of the utility functions, we have that

$$
\begin{aligned}
\lim _{n \rightarrow \infty} u^{f}\left(\widetilde{A}_{n}^{f}\right) & =u^{f}\left(Y^{f}\right)>u^{f}\left(A^{f}\right), \\
\lim _{n \rightarrow \infty} u^{w}\left(\widetilde{A}_{n}^{w}\right) & =u^{w}\left(B^{w}\right)>u^{w}\left(A^{w}\right), \quad w \in w\left(B^{f}\right) .
\end{aligned}
$$

By continuity of the utility functions, there is $n^{\prime} \in \mathbb{N}$ such that, for every $n \geq n^{\prime}$,

$$
\begin{aligned}
& u^{f}\left(\widetilde{A}_{n}^{f}\right)>u^{f}\left(A_{n}^{f}\right), \\
& u^{w}\left(\widetilde{A}_{n}^{w}\right)>u^{w}\left(A_{n}^{w}\right), \quad w \in w\left(B^{f}\right) .
\end{aligned}
$$

We find that, for every $n \geq n^{\prime}$, the non-empty set $\left\{\widetilde{a}_{n}(y) \mid y \in B^{f}\right\} \subset \widetilde{Y}_{n} \backslash A_{n}$ is a blocking set for $A_{n}$, a contradiction to $A_{n}$ being a stable outcome of the economy $\mathcal{E}_{n}=\left(\widetilde{Y}_{n},\left(u^{i}\right)_{i \in I}\right)$. Consequently, $A$ satisfies Condition 2 of Definition 4.1.

All the examples presented in Section 2 satisfy the conditions of Theorem 5.5, so an expectational equilibrium exists in all these examples by virtue of Theorem 5.5.

Any set of sufficient conditions such that the set of stable outcomes is non-empty is a set of sufficient conditions for the existence of an expectational equilibrium by Corollary 4.4. For example, in a setting with strict preferences and a finite set of contracts, substitutability has been weakened to "bilateral substitutes" in Hatfield and Kojima (2010), a condition that reduces to standard substitutability in matching models with no terms of contract. Another example is the "gross substitutes and complements" condition in Sun and Yang (2006), which generalizes substitutability as defined in Kelso and Crawford (1982). ${ }^{3}$

\section{Monetary Economies}

We argue in this section that in economies where arbitrary transfers of money are feasible, as is the case in the assignment model of Shapley and Shubik (1971) presented in Example 2.2 and in the job matching with salaries model of Kelso and Crawford (1982) described in Example 2.4, an expectational equilibrium is equivalent to a standard competitive equilibrium.

We call an economy $\mathcal{E}=\left(\bar{Y},\left(u^{i}\right)_{i \in I}\right)$ a monetary economy if each contract $y \in \bar{Y}$ can be written as $y=(t, m)$, where $m \in \mathbb{R}$ is an amount of money that is transferred from the firm to the worker and $t$ belongs to some finite set of trades $T$. We have that $\bar{Y} \subset T \times \mathbb{R}$. A trade $t \in T$ covers all non-monetary aspects of the contract, so in particular the identities of the firm and worker involved in the contract, denoted by $f(t)$ and $w(t)$, respectively. We use $t(y)$ to denote the trade involved in contract $y \in \bar{Y}$ and $m(y)$ to denote the amount

\footnotetext{
${ }^{3}$ In the set-up of Kelso and Crawford (1982), it has been shown by Gul and Stacchetti (1999) that substitutability is a necessary condition if the class of preferences includes unit demand preferences.
} 
of money. Given a set of contracts $Y \subset \bar{Y}, t(Y)=\{t \in T \mid \exists y \in Y$ such that $t(y)=t\}$ denotes the set of trades related to the set of contracts $Y$. Without loss of generality, it is assumed that $t(\bar{Y})=T$. For $t \in T, Y_{t}=\{m \in \mathbb{R} \mid(t, m) \in Y\}$ are the possible monetary amounts associated to contracts in $Y$ with trade $t$. Given a finite set of contracts $Y \subset \bar{Y}$, $M(Y)=\sum_{y \in Y} m(y)$ denotes the total amount of money involved in the set of contracts $Y$.

Let some monetary economy $\mathcal{E}=\left(\bar{Y},\left(u^{i}\right)_{i \in I}\right)$ be given. The utility function of a firm $f \in F$ is strictly monotonic in money if for every $A^{f}, A^{\prime f} \in X^{f}$ such that $t\left(A^{f}\right)=t\left(A^{\prime f}\right)$ it holds that $u^{f}\left(A^{f}\right)<u^{f}\left(A^{\prime f}\right)$ if and only if $M\left(A^{f}\right)>M\left(A^{\prime f}\right)$. The utility function of a worker $w \in W$ is strictly monotonic in money if for every $A^{w}, A^{\prime w} \in X^{w}$ such that $t\left(A^{w}\right)=$ $t\left(A^{\prime w}\right)$ it holds that $u^{w}\left(A^{w}\right)<u^{w}\left(A^{\prime w}\right)$ if and only if $M\left(A^{w}\right)<M\left(A^{\prime w}\right)$. Reservation values are said to be bounded if for every $f \in F$ there is $m^{f} \in \mathbb{R}$ such that, for every $A^{f} \in X^{f}$ with $M\left(A^{f}\right) \geq m^{f}$, it holds that $u^{f}\left(A^{f}\right) \leq u^{f}(\emptyset)$ and for every $w \in W$ there is $m^{w} \in \mathbb{R}$ such that, for every $A^{w} \in X^{w}$ with $M\left(A^{w}\right) \leq m^{w}$, it holds that $u^{w}\left(A^{w}\right) \leq u^{w}(\emptyset)$.

The economy $\mathcal{E}=\left(\bar{Y},\left(u^{i}\right)_{i \in I}\right)$ is said to be a free-contracting monetary economy if there is a finite set of trades $T$ such that $\bar{Y}=T \times \mathbb{R}$.

EXAMPLE 6.1: Let there be a single firm $f$ and a single worker $w_{1}$. There is a labor contract $t_{1}$ under which the firm employs the worker. This contract is completely standardized as far as the non-monetary aspects are concerned. Utility functions are quasilinear in money, with $u^{f}\left(\left\{\left(t_{1}, 0\right)\right\}\right)=1.1$ and $u^{w_{1}}\left(\left\{\left(t_{1}, 0\right)\right\}\right)=-0.1$. In accordance with the assumptions made in Section 2, the utility of not signing a contract is equal to 0, so $u^{f}(\emptyset)=u^{w_{1}}(\emptyset)=0$. In the free-contracting monetary economy it holds that

$$
\begin{aligned}
X^{f} & =\left\{\left\{\left(t_{1}, m\right)\right\} \mid m \in \mathbb{R}\right\} \cup\{\emptyset\}, \\
X^{w_{1}} & =\left\{\left\{\left(t_{1}, m\right)\right\} \mid m \in \mathbb{R}\right\} \cup\{\emptyset\} .
\end{aligned}
$$

Let $\left(A^{*}, Q^{*}, R^{*}\right)$ be an expectational equilibrium.

Suppose $A^{*}=\emptyset$. It follows that $\emptyset \in \delta^{f}\left(Q^{* f}\right)$, so $(-\infty, 1.1) \subset Q_{t_{1}}^{*}$ as otherwise the firm would demand a contract with the worker for a wage less than 1.1. It also holds that $\emptyset \in \delta^{w_{1}}\left(R^{* w_{1}}\right)$, so $(0.1,+\infty) \subset R_{t_{1}}^{*}$ as otherwise the worker would demand a contract with the firm at a wage above 0.1 . We find that $(0.1,1.1) \subset Q_{t_{1}}^{*} \cap R_{t_{1}}^{*}$, a contradiction to the market transparency required in Condition 3 of Definition 2.6. Consequently, it holds that $A^{*} \neq \emptyset$.

We have that for some $m^{*} \in \mathbb{R}, A^{*}=\left\{\left(t_{1}, m^{*}\right)\right\}$. From the requirements that $A^{* f} \in$ $\delta^{f}\left(Q^{* f}\right)$ and $A^{* w_{1}} \in \delta^{w_{1}}\left(R^{* w_{1}}\right)$, it follows that $m^{*} \in[0.1,1.1]$. It also follows that $m^{*} \notin Q_{t_{1}}^{* f}$, $m^{*} \notin R_{t_{1}}^{* w_{1}},\left(-\infty, m^{*}\right) \subset Q_{t_{1}}^{* f}$, and $\left(m^{*},+\infty\right) \subset R_{t_{1}}^{* w_{1}}$. By employing Condition 3 of Definition 2.6, market transparency, we find that for every $m^{*} \in[0.1,1.1]$ there is an expectational equilibrium given by $A^{*}=\left\{\left(t_{1}, m^{*}\right)\right\}, Q^{*}=\left\{t_{1}\right\} \times\left(-\infty, m^{*}\right)$, and $R^{*}=\left\{t_{1}\right\} \times\left(m^{*},+\infty\right) . \triangle$ 
In the expectational equilibrium of Example 6.1, the traded contract involves a wage equal to $m^{*} \in[0.1,1.1]$. The worker expects that the firm is not willing to trade a contact with a wage above $m^{*}$ and the firm expects that the worker is not willing to trade a contract with a wage below $m^{*}$. This is exactly in accordance with the usual notion of competitive equilibrium, where buyers expect no supply below the equilibrium price and sellers expect no demand above the equilibrium price.

In reality, money is not perfectly divisible, but there is a denomination $\mu>0$ such that all monetary amounts in contracts are integer multiples of $\mu$, so belong to the set

$$
M(\mu)=\{m \in \mathbb{R} \mid \exists k \in \mathbb{Z} \text { such that } m=k \mu\} .
$$

The economy $\mathcal{E}$ is a discrete free-contracting monetary economy if there is a finite set $T$ and $\mu>0$ such that $\bar{Y}=T \times M(\mu)$.

ExAmPle 6.2: Consider the discrete free-contracting economy resulting from $\mu=1$ that corresponds to Example 6.1. It follows that there is a single firm $f$, a single worker $w_{1}$, and a single labor contract $t_{1}$, standardized as far as non-monetary aspects are concerned. Utility functions are quasi-linear in money with $u^{f}\left(\left\{\left(0, t_{1}\right)\right\}\right)=1.1$ and $u^{w_{1}}\left(\left\{\left(0, t_{1}\right)\right\}\right)=$ -0.1 . The utility of not signing a contract is equal to 0 , so $u^{f}(\emptyset)=u^{w_{1}}(\emptyset)=0$. We have that

$$
\begin{aligned}
X^{f} & =\left\{\left\{\left(t_{1}, m\right)\right\} \mid m \in \mathbb{Z}\right\} \cup\{\emptyset\}, \\
X^{w_{1}} & =\left\{\left\{\left(t_{1}, m\right)\right\} \mid m \in \mathbb{Z}\right\} \cup\{\emptyset\} .
\end{aligned}
$$

Consider a set of rationing constraints $Q \in 2^{\bar{Y}}$. Let $\underline{p}_{t_{1}}(Q)$ be the infimum of the set $M(\mu) \backslash Q_{t_{1}}$, the lowest wage against which firm $f$ expects to be able to hire worker $w_{1}$. It holds that $\underline{p}_{t_{1}}(Q)=-\infty$ if $M(\mu) \backslash Q_{t_{1}} \neq \emptyset$ and has no minimum, $\underline{p}_{t_{1}}(Q) \in \mathbb{Z}$ if $M(\mu) \backslash Q_{t_{1}} \neq \emptyset$ and the minimum of this set exists, and $\underline{p}_{t_{1}}(Q)=+\infty$ if $M(\mu) \backslash Q_{t_{1}}=\emptyset$. It holds that $\delta^{f}\left(Q^{f}\right)=\emptyset$ if $\underline{p}_{t_{1}}(Q)=-\infty, \delta^{f}\left(Q^{f}\right)=\left\{\left\{\left(t_{1}, \underline{p}_{t_{1}}(Q)\right)\right\}\right\}$ if $\underline{p}_{t_{1}}(Q) \in \mathbb{Z}$ and $\underline{p}_{t_{1}}(Q) \leq 1$, and $\delta^{f}\left(Q^{f}\right)=\{\emptyset\}$ if $\underline{p}_{t_{1}}(Q) \geq 2$.

Similarly, consider a set of rationing constraints $R \in 2^{\bar{Y}}$. Let $\bar{p}_{t_{1}}(R)$ be the supremum of the set $M(\mu) \backslash R_{t_{1}}$, the highest wage worker $w_{1}$ expects to receive. It holds that $\bar{p}_{t_{1}}(R)=$ $+\infty$ if $M(\mu) \backslash R_{t_{1}} \neq \emptyset$ and has no maximum, $\bar{p}_{t_{1}}(R) \in \mathbb{Z}$ if $M(\mu) \backslash R_{t_{1}} \neq \emptyset$ and the maximum of this set exists, and $\bar{p}_{t_{1}}(R)=-\infty$ if $M(\mu) \backslash R_{t_{1}}=\emptyset$. It holds that $\delta^{w_{1}}\left(R^{w_{1}}\right)=\emptyset$ if $\bar{p}_{t_{1}}(R)=+\infty, \delta^{w_{1}}\left(R^{w_{1}}\right)=\left\{\left\{\left(t_{1}, \bar{p}_{t_{1}}(R)\right)\right\}\right\}$ if $\bar{p}_{t_{1}}(R) \in \mathbb{Z}$ and $\bar{p}_{t_{1}}(R) \geq 1$, and $\delta^{w_{1}}\left(R^{w_{1}}\right)=$ $\{\emptyset\}$ if $\bar{p}_{t_{1}}(R) \leq 0$.

Let $\left(A^{*}, Q^{*}, R^{*}\right)$ be an expectational equilibrium.

Suppose $A^{*}=\emptyset$. It follows that $\emptyset \in \delta^{f}\left(Q^{* f}\right)$, so $\underline{p}_{t_{1}}\left(Q^{*}\right) \geq 2$, and therefore

$$
2 \leq \inf M(\mu) \backslash Q_{t_{1}}^{*} \leq \inf R_{t_{1}}^{*} \leq 1+\sup M(\mu) \backslash R_{t_{1}}^{*}=1+\bar{p}_{t_{1}}\left(R^{*}\right),
$$


where the first inequality uses that $R_{t_{1}}^{*} \subset M(\mu) \backslash Q_{t_{1}}^{*}$. We have derived that $\bar{p}_{t_{1}}\left(R^{*}\right) \geq 1$. Since $\emptyset \in \delta^{w_{1}}\left(R^{* w_{1}}\right)$, it holds that $\bar{p}_{t_{1}}\left(R^{*}\right) \leq 0$ and we have obtained a contradiction. Consequently, it holds that $A^{*} \neq \emptyset$ and therefore $t\left(A^{*}\right)=\left\{t_{1}\right\}$.

From $t\left(A^{*}\right)=\left\{t_{1}\right\}$, we derive that $\underline{p}_{t_{1}}\left(Q^{*}\right) \leq 1$, so from $A^{* f} \in \delta^{f}\left(Q^{* f}\right)$, we have that $M\left(A^{*}\right) \leq 1$. At the same time, it holds that $\bar{p}_{t_{1}}\left(R^{*}\right) \geq 1$, so from $A^{* w_{1}} \in \delta^{w_{1}}\left(R^{* w_{1}}\right)$, we have that $M\left(A^{*}\right) \geq 1$. We conclude that $M\left(A^{*}\right)=\underline{p}_{t_{1}}\left(Q^{*}\right)=\bar{p}_{t_{1}}\left(R^{*}\right)=1$, so $A^{*}=\left\{\left(t_{1}, 1\right)\right\}$. We show next that $Q^{*}$ and $R^{*}$ are uniquely determined as well.

Suppose there is $m \in Q_{t_{1}}^{*}$ such that $m>1$. Since $Q^{*} \cap R^{*}=\emptyset$, we have that $m \in$ $M(\mu) \backslash R_{t_{1}}^{*}$, so $\bar{p}_{t_{1}}\left(R^{*}\right) \geq 2$, leading to a contradiction with $\bar{p}_{t_{1}}\left(R^{*}\right)=1$. Consequently, since $A^{*} \cap Q^{*}=\emptyset$ and $M\left(A^{*}\right)=1$, we have that $Q_{t_{1}}^{*} \subset(-\infty, 0] \cap \mathbb{Z}$. Now it follows that $Q_{t_{1}}^{*}=(-\infty, 0] \cap \mathbb{Z}$, since otherwise the firm would demand a contract with a wage below 1 .

Suppose there is $m \in R_{t_{1}}^{*}$ such that $m<1$. Since $Q^{*} \cap R^{*}=\emptyset$, we have that $m \in M(\mu) \backslash$ $Q_{t_{1}}^{*}$, so $\underline{p}_{t_{1}}\left(Q^{*}\right) \leq 0$, a contradiction with $\underline{p}_{t_{1}}\left(Q^{*}\right)=1$. Consequently, since $A^{*} \cap R^{*}=\emptyset$ and $M\left(A^{*}\right)=1$, we have that $R_{t_{1}}^{*} \subset[2,+\infty) \cap \mathbb{Z}$. Now it follows that $R_{t_{1}}^{*}=[2,+\infty) \cap \mathbb{Z}$, since otherwise the worker would demand a contract with a wage above 1 .

It is easy to check that $\left(A^{*}, Q^{*}, R^{*}\right)$ indeed satisfies the conditions of Definition 2.6, so is an expectational equilibrium.

Example 6.2 considers a discrete free-contracting monetary economy. The primitives are the same as in Example 6.1, except that there is a smallest unit of account equal to 1. There is now a unique expectational equilibrium where the labor of the worker is traded against a price of 1 . The firm expects that it is not possible to hire the worker against a lower wage and the worker expects that the firm is not willing to offer a better wage.

For a monetary economy $\mathcal{E}$, we can also define the notion of a Walrasian equilibrium. Firms and workers optimize utility while taking prices for trades $p \in \prod_{t \in T} \bar{Y}_{t}$ as given. The budget set of a firm $f \in F$ is given by

$$
B^{f}(p)=\left\{A^{f} \in X^{f} \mid \forall y \in A^{f}, m(y)=p_{t(y)}\right\}, \quad p \in \prod_{t \in T} \bar{Y}_{t} .
$$

The demand correspondence $D^{f}$ of firm $f$ is defined by

$$
D^{f}(p)=\arg \max _{A^{f} \in B^{f}(p)} u^{f}\left(A^{f}\right), \quad p \in \prod_{t \in T} \bar{Y}_{t}
$$

Similarly, the budget set of a worker $w \in W$ is given by

$$
B^{w}(p)=\left\{A^{w} \in X^{w} \mid \forall y \in A^{w}, m(y)=p_{t(y)}\right\}, \quad p \in \prod_{t \in T} \bar{Y}_{t}
$$


and the demand correspondence $D^{w}$ of worker $w$ by

$$
D^{w}(p)=\arg \max _{A^{w} \in B^{w}(p)} u^{w}\left(A^{w}\right), \quad p \in \prod_{t \in T} \bar{Y}_{t}
$$

We have followed the usual convention and write $B^{f}, B^{w}, D^{f}$, and $D^{w}$ as a function of the entire price vector $p$. It is clearly sufficient to restrict attention to those prices that belong to trades that the agent is part of.

Definition 6.3: A Walrasian equilibrium of the monetary economy $\mathcal{E}=\left(\bar{Y},\left(u^{i}\right)_{i \in I}\right)$ is an element $\left(A^{*}, p^{*}\right) \in \mathcal{A} \times \prod_{t \in T} \bar{Y}_{t}$ such that, for every $i \in I, A^{* i} \in D^{i}\left(p^{*}\right)$.

Definition 6.3 requires optimization by firms and workers that take prices $p^{*} \in \prod_{t \in T} \bar{Y}_{t}$ as given. The usual market clearing condition in a Walrasian equilibrium is not needed, since for every contract in $A^{*}$ it holds that both the firm and the worker are demanding it.

Example 6.4: Consider the primitives of Example 6.2. It holds that $D^{f}(p)=$ $\left\{\left\{\left(t_{1}, p\right)\right\}\right\}$ if $p \leq 1$ and $D^{f}(p)=\{\emptyset\}$ if $p \geq 2$. Also, we have that $D^{w}(p)=\left\{\left\{\left(t_{1}, p\right)\right\}\right\}$ if $p \geq 1$ and $D^{w}(p)=\{\emptyset\}$ if $p \leq 0$. It is now immediate that $\left(A^{*}, p^{*}\right) \in \mathcal{A} \times M(\mu)$ is a Walrasian equilibrium if and only if $A^{*}=\left\{\left(t_{1}, 1\right)\right\}$ and $p^{*}=1$.

For a given price vector $p \in \prod_{t \in T} \bar{Y}_{t}$, firms implicitly expect that there is no possibility to carry out a trade $t \in T$ against a price below $p_{t}$. It therefore makes sense to define the set of rationing constraints $Q(p)$ by

$$
Q(p)=\left\{y \in \bar{Y} \mid m(y)<p_{t(y)}\right\} .
$$

Similarly, for a given price vector $p \in \prod_{t \in T} \bar{Y}_{t}$, workers implicitly expect that it is not feasible to receive a wage above $p_{t}$ for trade $t$. We define the set of demand rationing constraints $R(p)$ by

$$
R(p)=\left\{y \in \bar{Y} \mid m(y)>p_{t(y)}\right\}
$$

TheOREM 6.5: Let $\left(A^{*}, p^{*}\right)$ be a Walrasian equilibrium of the monetary economy $\mathcal{E}=$ $\left(\bar{Y},\left(u^{i}\right)_{i \in I}\right)$. Then $\left(A^{*}, Q\left(p^{*}\right), R\left(p^{*}\right)\right)$ is an expectational equilibrium of $\mathcal{E}$.

Proof: We define $Q^{*}=Q\left(p^{*}\right)$ and $R^{*}=R\left(p^{*}\right)$ and show that $\left(A^{*}, Q^{*}, R^{*}\right)$ satisfies the three conditions of Definition 2.6.

Suppose there is $f \in F$ such that $A^{* f} \notin \delta^{f}\left(Q^{* f}\right)$. Then there is $A^{f} \in \beta^{f}\left(Q^{* f}\right)$ such that $u^{f}\left(A^{f}\right)>u^{f}\left(A^{* f}\right)$. Since $\emptyset \in \beta^{f}\left(Q^{* f}\right)$, it holds that $u^{f}\left(A^{* f}\right) \geq 0$, so $u^{f}\left(A^{f}\right)>0$ and 
$A^{f} \neq \emptyset$. Let

$$
\widetilde{A}^{f}=\left\{(t, m) \in t\left(A^{f}\right) \times \mathbb{R} \mid m=p_{t}^{*}\right\}
$$

be the contracts in $A^{f}$ where the monetary part of the contract has been replaced by the Walrasian equilibrium price. Since, for every $t \in T, p_{t}^{*} \in \bar{Y}_{t}$, it holds that $\widetilde{A}^{f} \in X^{f}$. It is then immediate that $\widetilde{A}^{f} \in B^{f}\left(p^{*}\right)$. Using the definition of $Q^{*}$, we have that $M\left(\widetilde{A}^{f}\right) \leq$ $M\left(A^{f}\right)$, so $u^{f}\left(\widetilde{A}^{f}\right) \geq u^{f}\left(A^{f}\right)>u^{f}\left(A^{* f}\right)$, leading to a contradiction with $A^{* f} \in D^{f}\left(p^{*}\right)$. Consequently, it holds that, for every $f \in F, A^{* f} \in \delta^{f}\left(Q^{* f}\right)$.

An analogous argument can be used to show that, for every $w \in W, A^{* w} \in \delta^{w}\left(R^{* w}\right)$.

It follows immediately from the definition of $Q^{*}$ and $R^{*}$ that $Q^{*} \cap R^{*}=\emptyset$.

We have shown that $\left(A^{*}, Q^{*}, R^{*}\right)$ is an expectational equilibrium of $\mathcal{E}$.

The result of Theorem 6.5 applies to any monetary economy, so is not restricted to the free-contracting monetary economy or the discrete free-contracting monetary economy.

When is an expectational equilibrium $\left(A^{*}, Q^{*}, R^{*}\right)$ a Walrasian equilibrium? Then there should be a price system such that all markets clear. For every contract $y$ that belongs to $A^{*}$, the natural candidate for the price is $m(y)$. The firm is willing to demand and the worker is willing to supply at that price. The next result shows that market clearing prices can always be found in a free-contracting monetary economy.

THEOREM 6.6: Let $\mathcal{E}=\left(\bar{Y},\left(u^{i}\right)_{i \in I}\right)$ be a free-contracting monetary economy with continuous utility functions and let $\left(A^{*}, Q^{*}, R^{*}\right)$ be an expectational equilibrium of $\mathcal{E}$. Then there is $p^{*} \in \mathbb{R}^{T}$ such that $\left(A^{*}, p^{*}\right)$ is a Walrasian equilibrium of $\mathcal{E}$.

Proof: We first define prices $p^{*} \in \mathbb{R}^{T}$. To do so, we divide $T$ in five mutually exclusive subsets $T_{1}, \ldots, T_{5}$. The set of trades that are part of the expectational equilibrium outcome are denoted by $T_{1}$. The set of trades that are not part of an expectational equilibrium outcome, but for which there is an amount of money for which neither the firm nor the worker involved expects rationing is given by $T_{2}$. The trades in $T_{3}, T_{4}$, and $T_{5}$ are such that for every amount of money either the firm or the worker expects rationing. Trades in $T_{3}$ are such that both the worker and the firm expect rationing for some amounts of money, for trades in $T_{4}$ the firm never expects rationing, and for trades in $T_{5}$ the worker never expects rationing. More formally, we have

$$
\begin{aligned}
& T_{1}=t\left(A^{*}\right), \\
& T_{2}=\left\{t \in T \backslash t\left(A^{*}\right) \mid Q_{t}^{*} \cup R_{t}^{*} \neq \mathbb{R}\right\}, \\
& T_{3}=\left\{t \in T \mid Q_{t}^{*} \neq \emptyset, R_{t}^{*} \neq \emptyset, \text { and } Q_{t}^{*} \cup R_{t}^{*}=\mathbb{R}\right\}, \\
& T_{4}=\left\{t \in T \mid R_{t}^{*}=\mathbb{R}\right\}, \\
& T_{5}=\left\{t \in T \mid Q_{t}^{*}=\mathbb{R}\right\} .
\end{aligned}
$$


For every $t \in T_{1}$, let $p_{t}^{*}=m$, where $m$ is such that $(t, m) \in A^{*}$. For every $t \in T_{2}$, choose an element $p_{t}^{*}$ in $\mathbb{R} \backslash\left(Q_{t}^{*} \cup R_{t}^{*}\right)$. For every $t \in T_{3}$, choose an element $p_{t}^{*}$ in $\operatorname{cl}\left(Q_{t}^{*}\right) \cap \operatorname{cl}\left(R_{t}^{*}\right)$, where cl denotes the closure of a set. Since $\mathbb{R}$ is connected, it follows that $\operatorname{cl}\left(Q_{t}^{*}\right) \cap \operatorname{cl}\left(R_{t}^{*}\right) \neq \emptyset$. For every $t \in T_{4}$, define $p_{t}^{*}=m^{w(t)}$.

For trades in $T_{5}$ we choose the price to be sufficiently high such that a contract for that price is never chosen by the firm involved. More precisely, for every $f \in F$, recall that $T^{f}$ are the trades in $T$ involving firm $f$ and define

$$
\widetilde{m}^{f}=\sum_{t \in\left(T_{1} \cup T_{2} \cup T_{3} \cup T_{4}\right) \cap T^{f}} \max \left\{0,-p_{t}^{*}\right\}
$$

where we use the convention that the sum over the empty set is zero. For every $t \in T_{5}$, we define $p_{t}^{*}=\widetilde{m}^{f}+\max \left\{0, m^{f}\right\}$.

We now verify that $\left(A^{*}, p^{*}\right)$ satisfies the three conditions of Definition 6.3.

Let some $f \in F$ be given. By the definition of $p_{t}^{*}$ for $t \in T_{1}$, it follows immediately that $A^{* f} \in B^{f}\left(p^{*}\right)$.

Suppose $A^{* f} \notin D^{f}\left(p^{*}\right)$, so there is $A^{f} \in B^{f}\left(p^{*}\right)$ such that $u^{f}\left(A^{f}\right)>u^{f}\left(A^{* f}\right)$. If there is $t \in T_{5}$ such that $t \in t\left(A^{f}\right)$, then

$$
\begin{aligned}
M\left(A^{f}\right) & =\sum_{t \in t\left(A^{f}\right)} p_{t}^{*} \\
& =\sum_{t \in\left(T_{1} \cup T_{2} \cup T_{3} \cup T_{4} \cup T_{5}\right) \cap t\left(A^{f}\right)} p_{t}^{*} \\
& \geq-\widetilde{m}^{f}+\sum_{t \in T_{5} \cap t\left(A^{f}\right)} p_{t}^{*} \\
& \geq-\widetilde{m}^{f}+\widetilde{m}^{f}+\max \left\{0, m^{f}\right\} \\
& \geq m^{f}
\end{aligned}
$$

so $u^{f}\left(A^{f}\right) \leq u^{f}(\emptyset) \leq u^{f}\left(A^{* f}\right)$. It follows that $t\left(A^{f}\right) \cap T_{5}=\emptyset$. For every $\varepsilon>0$, for every $t \in t\left(A^{* f}\right) \cap T_{3}$, from the fact that $p_{t}^{*} \in \operatorname{cl}\left(R_{t}^{*}\right)$, there exists $\widetilde{p}_{t} \in R_{t}^{*}$ such that $\left|\widetilde{p}_{t}-p_{t}^{*}\right| \leq \varepsilon$. From Condition 3 in Definition 2.6 of an expectational equilibrium, we have that $\widetilde{p}_{t} \notin Q_{t}^{*}$. We define

$$
\widetilde{A}^{f}=\left\{y \in A^{f} \mid t(y) \notin T_{3}\right\} \cup\left\{y \in A^{f} \mid t(y) \in T_{3} \text { and } m(y)=\widetilde{p}_{t(y)}\right\},
$$

so $\widetilde{A}^{f}$ results from $A^{f}$ by changing the price of trades $t$ in $t\left(A^{f}\right) \cap T_{3}$ from $p_{t}^{*}$ to $\widetilde{p}_{t}$. Since $\widetilde{A}^{f} \cap Q^{* f}=\emptyset$, it holds that $\widetilde{A}^{f} \in \beta^{f}\left(Q^{* f}\right)$. By continuity of $u^{f}$ it holds that for $\varepsilon>0$ sufficiently small, $u^{f}\left(\widetilde{A}^{f}\right)>u^{f}\left(A^{* f}\right)$, contradicting that $A^{* f} \in \delta^{f}\left(Q^{* f}\right)$. Consequently, it holds that $A^{* f} \in D^{f}\left(p^{*}\right)$.

Let some $w \in W$ be given. By the definition of $p_{t}^{*}$ for $t \in T_{1}$, it follows immediately that $A^{* w} \in B^{w}\left(p^{*}\right)$.

Suppose $A^{* w} \notin D^{w}\left(p^{*}\right)$, so there is $A^{w}=\left\{\left(t, p_{t}^{*}\right)\right\} \in B^{w}\left(p^{*}\right)$ such that $u^{w}\left(\left\{\left(t, p_{t}^{*}\right)\right\}\right)>$ $u^{w}\left(A^{* w}\right)$. Since $A^{w} \neq A^{* w}$, it holds that $t \notin T_{1}$. From $A^{w} \notin \beta^{w}\left(R^{* w}\right)$, it follows that $p_{t}^{*} \in R_{t}^{*}$, 
so $t \notin T_{2} \cup T_{5}$. If $t \in T_{4}$, then $p_{t}^{*}=m^{w}$, so it holds that $u^{w}\left(A^{w}\right) \leq u^{w}(\emptyset) \leq u^{w}\left(A^{* w}\right)$, so the only possibility is that $t \in T_{3}$.

Suppose $t \in T_{3}$. From $A^{w} \notin \beta^{w}\left(R^{* w}\right)$, it follows that $p_{t}^{*} \in R_{t}^{*}$. Since $p_{t}^{*} \in \operatorname{cl}\left(Q_{t}^{*}\right)$, for every $\varepsilon>0$, there exists $\widetilde{p}_{t} \in Q_{t}^{*}$ such that $\left|\widetilde{p}_{t}-p_{t}^{*}\right| \leq \varepsilon$. From Condition 3 in the definition of an expectational equilibrium, we have that $\widetilde{p}_{t} \notin R_{t}^{*}$. It follows that $\left\{\left(t, \widetilde{p}_{t}\right)\right\} \in \beta^{w}\left(R^{* w}\right)$ and, by continuity of $u^{w}$, for $\varepsilon>0$ sufficiently small, $u^{w}\left(\left\{\left(t, \widetilde{p}_{t}\right)\right\}\right)>u^{w}\left(A^{* w}\right)$, leading to a contradiction. Consequently, it holds that $t \notin T_{3}$.

We conclude that $A^{* w} \in D^{w}\left(p^{*}\right)$.

The final condition of a Walrasian equilibrium, for every $t \in T, p_{t}^{*} \in \bar{Y}_{t}$, follows immediately from the fact that $\mathcal{E}$ is a free-contracting monetary economy, which implies that $\bar{Y}_{t}=\mathbb{R}$.

Under the conditions in Theorem 6.6, we obtain an equivalence between expectational equilibria and Walrasian equilibria. These conditions do not require substitutability, but only continuity of utility functions and the absence of restrictions on monetary transfers that are allowed. These conditions are for instance satisfied in the set-up of Sun and Yang (2004), where utility functions are quasi-linear and satisfy the gross substitutes and complements condition. Sun and Yang (2004) demonstrate the existence of Walrasian equilibria, which are equivalent to expectational equilibria by Theorems 6.5 and 6.6.

EXAMPLE 6.7: We take the primitives of Example 6.2, but now introduce a second worker, $w_{2}$. The labor contract under which firm $f$ employs worker $w_{2}$ is denoted by $t_{2}$. The firm slightly prefers $w_{2}$ over $w_{1}, u^{f}\left(t_{2}, 0\right)=1.2$, whereas $u^{w_{2}}\left(t_{2}, 0\right)=-0.2$. The utility of $w_{2}$ when not signing a contract is $u^{w_{2}}(\emptyset)=0$. The firm needs only one worker, $u^{f}\left(\left\{\left(t_{1}, 0\right),\left(t_{2}, 0\right)\right\}\right)=u^{f}\left(\left\{\left(t_{2}, 0\right)\right\}\right)=1.2$. As in Example 6.2, we study the discrete freecontracting economy. We argue next that this economy has no Walrasian equilibrium.

Suppose $\left(A^{*}, p^{*}\right) \in \mathcal{A} \times \prod_{t \in T} \bar{Y}_{t}$ is a Walrasian equilibrium of the economy. There are four possibilities: Case 1. $t\left(A^{*}\right)=\emptyset$, Case 2. $t\left(A^{*}\right)=\left\{t_{1}\right\}$, Case 3. $t\left(A^{*}\right)=\left\{t_{2}\right\}$, and Case 4. $t\left(A^{*}\right)=\left\{t_{1}, t_{2}\right\}$. We show that each of these cases leads to a contradiction.

Case 1. $t\left(A^{*}\right)=\emptyset$.

Optimization by workers implies that $p_{t_{1}}^{*} \leq 0$ and $p_{t_{2}}^{*} \leq 0$. Signing a contract with worker $w_{1}$ against a wage $p_{t_{1}}^{*}$ is now preferred by the firm to not signing a contract, a contradiction with $\emptyset \in D^{f}\left(p^{*}\right)$.

Case 2. $t\left(A^{*}\right)=\left\{t_{1}\right\}$.

Optimization by workers implies that $p_{t_{1}}^{*} \geq 1$ and $p_{t_{2}}^{*} \leq 0$. Since

$$
u^{f}\left(A^{* f}\right) \leq 1.1-1<1.2 \leq u^{f}\left(\left\{\left(t_{2}, p_{t_{2}}^{*}\right)\right\}\right),
$$

it follows that $\left\{\left(t_{1}, p_{t_{1}}^{*}\right)\right\} \notin D^{f}\left(p^{*}\right)$, a contradiction to $\left(A^{*}, p^{*}\right)$ being a Walrasian equilib- 
rium.

Case 3. $t\left(A^{*}\right)=\left\{t_{2}\right\}$.

Optimization by workers implies that $p_{t_{1}}^{*} \leq 0$ and $p_{t_{2}}^{*} \geq 1$. Since

$$
u^{f}\left(A^{* f}\right) \leq 1.2-1<1.1 \leq u^{f}\left(\left\{\left(t_{1}, p_{t_{1}}^{*}\right)\right\}\right),
$$

it follows that $\left\{\left(t_{2}, p_{t_{2}}^{*}\right)\right\} \notin D^{f}\left(p^{*}\right)$, a contradiction to $\left(A^{*}, p^{*}\right)$ being a Walrasian equilibrium.

Case 4. $t\left(A^{*}\right)=\left\{t_{1}, t_{2}\right\}$.

Optimization by workers implies that $p_{t_{1}}^{*} \geq 1$ and $p_{t_{2}}^{*} \geq 1$. Since

$$
u^{f}\left(A^{* f}\right) \leq 1.2-2<0=u^{f}(\emptyset)
$$

the firm is better off by not signing any contract, leading to a contradiction.

We conclude that the economy does not have a Walrasian equilibrium.

The reason that the economy of Example 6.7 does not have a Walrasian equilibrium is the existence of a smallest unit of account, $\mu$. If prices could be any real number, then there is a Walrasian equilibrium with prices $p^{*} \in \mathbb{R}^{T}$ where firm $f$ signs a contract with worker $w_{2}$. In order to weakly improve upon not signing a contract, it should hold that $p_{t_{2}}^{*} \in[0.2,1.2]$. To ensure the firm doesn't hire worker $w_{1}$ instead of $w_{2}$, it should hold that $p_{t_{1}}^{*} \geq p_{t_{2}}^{*}-0.1$. To make it rational for worker $w_{1}$ not to demand a labor contract, it should hold that $p_{t_{1}}^{*} \leq 0.1$. Without a smallest unit of account, Walrasian equilibrium prices are unique and equal to $\left(p_{t_{1}}^{*}, p_{t_{2}}^{*}\right)=(0.1,0.2)$. These prices also admit a Walrasian equilibrium where the firm $f$ contracts with worker $w_{1}$. Walrasian equilibrium prices are unique, but the allocation is not in this particular case.

We show that for the primitives of Example 6.7, expectational equilibrium does not suffer from existence issues.

EXAMPLE 6.8: We consider the primitives of Example 6.7 and analyze the concept of expectational equilibrium. We argue that there is a unique expectational equilibrium, where firm $f$ hires worker $w_{2}$ and both sign the contract $\left(t_{2}, 1\right)$. To be more precise, this expectational equilibrium is obtained by setting

$$
\begin{aligned}
& A^{*}=\left\{\left(t_{2}, 1\right)\right\}, \\
& Q^{*}=\left(\left\{t_{1}\right\} \times((-\infty, 0] \cap \mathbb{Z})\right) \cup\left(\left\{t_{2}\right\} \times((-\infty, 0] \cap \mathbb{Z})\right), \\
& R^{*}=\left(\left\{t_{1}\right\} \times([1,+\infty) \cap \mathbb{Z})\right) \cup\left(\left\{t_{2}\right\} \times([2,+\infty) \cap \mathbb{Z})\right) .
\end{aligned}
$$

The firm has the choice between not signing a contract, hiring $w_{1}$ against a wage at least equal to 1 , or hiring $w_{2}$ against a wage at least equal to 1 . Hiring $w_{2}$ against a wage equal 
to 1 is optimal for firm $f$. Worker $w_{1}$ has the choice between not signing a contract or working for firm $f$ against a wage less than or equal to 0 . The optimal choice of $w_{1}$ is not to sign a contract. Worker $w_{2}$ has the choice between not signing a contract or working for firm $f$ against a wage less than or equal to 1 . Signing a contract with firm $f$ against a wage equal to 1 is clearly optimal for $w_{2}$. It is immediately verified that $Q^{*} \cap R^{*}=\emptyset$. All conditions of Definition 2.6 are met, so $\left(A^{*}, Q^{*}, R^{*}\right)$ is an expectational equilibrium.

For any denomination $\mu$, it holds that the discrete free-contracting monetary economies corresponding to the assignment model of Shapley and Shubik (1971) in Example 2.2 and the job matching with salaries model of Kelso and Crawford (1982) satisfy substitutability. Since also the other conditions in Theorem 6.5 are met, we conclude that expectational equilibria exist in such economies, whereas Walrasian equilibria clearly may not.

\section{Economies with Price Controls}

For economies in which all commodities are perfectly divisible, there is an extensive literature on competitive equilibrium under price controls, starting with the contributions by Bénassy (1975), Drèze (1975), and Younès (1975). In the presence of price controls, Walrasian equilibria often fail to exist as it can easily be the case that every Walrasian equilibrium violates the restrictions as imposed by the price controls. Hatfield, Plott, and Tanaka $(2012,2016)$ therefore advocate to use the matching approach in the analysis. Herings (2018) studies the model of Example 2.3 and adapts the concept by Drèze (1975) to one-to-one matching models subject to price controls. We now extend this concept to monetary economies as defined in Section 6.

The economy $\mathcal{E}=\left(\bar{Y},\left(u^{i}\right)_{i \in I}\right)$ is said to be a monetary economy subject to price controls if there is a finite set of trades $T$, a vector of price floors $p \in(\{-\infty\} \cup \mathbb{R})^{T}$, and a vector of price ceilings $\bar{p} \in(\mathbb{R} \cup\{+\infty\})^{T}$ such that $\underline{p} \leq \bar{p}$ and

$$
\bar{Y}=\left\{(t, m) \in T \times \mathbb{R} \mid \underline{p}_{t} \leq m \leq \bar{p}_{t}\right\}
$$

The free-contracting monetary economy in Section 6 results as the special case where, for every $t \in T, \underline{p}_{t}=-\infty$ and $\bar{p}_{t}=+\infty$. All the examples in Section 2 are special cases as well. As an illustration, one obtains the marriage problem of Gale and Shapley (1962) in Example 2.1 by taking $T=F \times W$, for every $t \in T, \underline{p}_{t}=\bar{p}_{t}=0$, and defines utility functions such that firms never want to hire more than one worker.

We define the notion of a Drèze equilibrium for a monetary economy subject to price controls. Firms and workers optimize utility while taking prices and rationing constraints $(p, q, r) \in \mathbb{R}^{T} \times\{0,1\}^{T} \times\{0,1\}^{T}$ as given. Consider some $t \in T$. The interpretation of 
$q_{t}=0$ is that firm $f(t)$ experiences no rationing in trade $t$, whereas $q_{t}=1$ means that firm $f(t)$ is rationed on trade $t$. Similarly, $r_{t}=0$ means that worker $w(t)$ expects no rationing for trade $t$, whereas in case $r_{t}=1$ worker $w(t)$ is rationed on trade $t$. The budget set of a firm $f \in F$ is given by

$$
B^{f}(p, q)=\left\{A^{f} \in X^{f} \mid \forall y \in A^{f}, m(y)=p_{t(y)} \text { and } q_{t(y)}=0\right\}, \quad p \in \mathbb{R}^{T}, q \in\{0,1\}^{T} .
$$

The demand correspondence $D^{f}$ of firm $f$ is defined by

$$
D^{f}(p, q)=\arg \max _{A^{f} \in B^{f}(p, q)} u^{f}\left(A^{f}\right), \quad p \in \mathbb{R}^{T}, q \in\{0,1\}^{T}
$$

Similarly, the budget set of a worker $w \in W$ is given by

$$
B^{w}(p, r)=\left\{A^{w} \in X^{w} \mid \forall y \in A^{w}, m(y)=p_{t(y)} \text { and } r_{t(y)}=0\right\}, \quad p \in \mathbb{R}^{T}, r \in\{0,1\}^{T},
$$

and the demand correspondence $D^{w}$ of worker $w$ by

$$
D^{w}(p, r)=\arg \max _{A^{w} \in B^{w}(p, r)} u^{w}\left(A^{w}\right), \quad p \in \mathbb{R}^{T}, r \in\{0,1\}^{T} .
$$

To simplify notation, we have written $B^{f}, B^{w}, D^{f}$, and $D^{w}$ as functions of the entire vectors $p, q$, and $r$. It suffices to restrict attention to those components of these vectors that correspond to the trades the agent is involved in.

The definition of Drèze equilibrium is now as follows, where the set $[\underline{p}, \bar{p}]$ denotes the set of price vectors in between the price floors $\underline{p}$ and the price ceilings $\bar{p}$.

Definition 7.1: A Drèze equilibrium of the monetary economy subject to price controls $\mathcal{E}=\left(\bar{Y},\left(u^{i}\right)_{i \in I}\right)$ is an element $\left(A^{*}, p^{*}, q^{*}, r^{*}\right) \in \mathcal{A} \times[\underline{p}, \bar{p}] \times\{0,1\}^{T} \times\{0,1\}^{T}$ such that:

1. For every $f \in F, A^{* f} \in D^{f}\left(p^{*}, q^{*}\right)$.

2. For every $w \in W, A^{* w} \in D^{w}\left(p^{*}, r^{*}\right)$.

3. For every $t \in T$, if $p_{t}^{*}<\bar{p}_{t}$, then $q_{t}^{*}=0$.

4. For every $t \in T$, if $p_{t}^{*}>\underline{p}_{t}$, then $r_{t}^{*}=0$.

5. For every $t \in T, q_{t}^{*}=0$ or $r_{t}^{*}=0$.

The first two conditions in Definition 7.1 reflect standard optimization by the firms and the workers. Firms and workers only need to know the given prices and their individual rationing scheme and need not consider the other individuals in making their decisions. 
Condition 3 states that whenever the price of a trade $t$ is upwards flexible, i.e., strictly below the price ceiling $\bar{p}_{t}$, then there is no rationing of firm $f(t)$. Similarly, Condition 4 states that whenever the price of a trade $t$ is downwards flexible, i.e., strictly above the price floor $\underline{p}_{t}$, then there is no rationing of worker $w(t)$. Condition 5 expresses that markets are transparent. There is no simultaneous rationing of workers and firms for a given trade $t$.

In the special case where all price floors are equal to $-\infty$ and all price ceilings are equal to $+\infty$, Definition 7.1 of a Drèze equilibrium reduces to Definition 6.3 of a Walrasian equilibrium. The concept of an expectational equilibrium is richer, since it expresses expectations for every possible contract, whereas a Drèze equilibrium only involves expectations for the contract where the price of the trade is equal to the equilibrium price.

EXAmPle 7.2: Consider the primitives of Example 6.1, but assume that there is a legal minimum wage equal to 1 , which has to be respected by any contract the firm and the worker sign. In the resulting monetary economy subject to price controls it holds that

$$
\begin{aligned}
X^{f} & =\left\{\left\{\left(t_{1}, m\right)\right\} \mid m \in[1,+\infty)\right\} \cup\{\emptyset\}, \\
X^{w_{1}} & =\left\{\left\{\left(t_{1}, m\right)\right\} \mid m \in[1,+\infty)\right\} \cup\{\emptyset\} .
\end{aligned}
$$

Since there is no price ceiling on the wage of the worker, by Condition 3 of Definition 7.1 it holds that $q_{t_{1}}^{*}=0$, so the firm expects no rationing. Potentially, there are two types of Drèze equilibria. One where the worker is not rationed and one where the worker is.

Consider Drèze equilibria of the first type, so without any rationing. These are simply the Walrasian equilibria of the economy with the worker's wage greater than or equal to the minimum wage, and therefore given by $\left(A^{*}, p^{*}, q^{*}, r^{*}\right)$ such that $A^{*}=\left\{\left(t_{1}, p^{*}\right)\right\}$, $p^{*} \in[1,1.1], q^{*}=0$, and $r^{*}=0$. At a wage of 1.1 the firm is indifferent between hiring and not hiring the worker. However, the worker takes the wage 1.1 as given and is supplying the contract $\left(t_{1}, 1.1\right)$. Therefore, there is no Drèze equilibrium without rationing and without trade.

Next we consider Drèze equilibria of the second type, so with rationing of the worker, i.e. $r^{*}=r_{t_{1}}^{*}=1$. Trivially, the optimal choice for the worker is now to stay inactive, i.e. not sign any contract. It follows from Condition 4 of Definition 7.1 that the wage $p^{*}$ is equal to the legal minimum wage $\underline{p}_{t_{1}}^{*}=1$. At this wage, the firm demands the contract $\left(t_{1}, 1\right)$, so there is no such equilibrium.

Since all Drèze equilibria are Walrasian equilibria it holds by Theorem 6.5 that for every Drèze equilibrium $\left(A^{*}, p^{*}, q^{*}, r^{*}\right)$ there is an expectational equilibrium $\left(A^{*}, Q^{*}, R^{*}\right)$ with $Q^{*}=Q\left(p^{*}\right)=\left\{y \in \bar{Y} \mid m(y)<p_{t(y)}^{*}\right\}=\left\{\left(t_{1}, m\right) \mid m<p_{t_{1}}^{*}\right\}$ and $R^{*}=R\left(p^{*}\right)=$ $\left\{y \in \bar{Y} \mid m(y)>p_{t(y)}^{*}\right\}=\left\{\left(t_{1}, m\right) \mid m>p_{t_{1}}^{*}\right\}$. It can be verified that there are no other expectational equilibria. 
Assume now that the legal minimum wage is raised to 2. We have that

$$
\begin{aligned}
X^{f} & =\left\{\left\{\left(t_{1}, m\right)\right\} \mid m \in[2,+\infty)\right\} \cup\{\emptyset\}, \\
X^{w_{1}} & =\left\{\left\{\left(t_{1}, m\right)\right\} \mid m \in[2,+\infty)\right\} \cup\{\emptyset\} .
\end{aligned}
$$

As long as the wage is above 2, then rationing of the worker is not allowed by Condition 4 of Definition 7.1. At such a wage, the worker will demand the contract, whereas the firm will not, and there is no equilibrium. At a wage of 2, we obtain an equilibrium with rationing of the worker, $r_{t_{1}}^{*}=1$, and both the worker and the firm not expressing demand for the contract. The worker because of rationing and the firm because of the wage that is too high. The worker is unemployed and rationally expects no employment at a wage of 2 .

There cannot be an expectational equilibrium involving trade, since the firm is never going to demand a contract with a wage greater than or equal to 2. All expectational equilibria therefore have the outcome $A^{*}=\emptyset$. To make it optimal for the worker not to demand any contract, it should be that $R^{*}=\bar{Y}$. By Condition 3 of Definition 2.6, it follows that the firm faces no restrictions, $Q^{*}=\emptyset$. Since every contract in $\bar{Y}$ involves a wage above the productivity of the worker, the firm optimally demands no contract. There is a unique expectational equilibrium with the same outcome as the Drèze equilibrium.

For given prices $p \in[\underline{p}, \bar{p}]$, firms implicitly expect that there is no possibility to carry out a trade $t \in T$ against a price below $p_{t}$. If, moreover, $q_{t}=1$, then also trade at price $p_{t}$ is expected to be impossible, and by Condition 3 of Definition 7.1, $p_{t}=\bar{p}_{t}$. In order to obtain an expectational equilibrium, it therefore makes sense to define the set of rationing constraints $Q(p, q)$ by

$$
Q(p, q)=\left\{y \in \bar{Y} \mid m(y)<p_{t(y)} \text { if } q_{t(y)}=0 \text { and } m(y) \leq p_{t(y)} \text { if } q_{t(y)}=1\right\} .
$$

Analogously, for given prices $p \in[p, \bar{p}]$, workers implicitly expect that it is not feasible to receive a wage above $p_{t}$ for trade $t$. If, moreover, $r_{t}=1$, then also trade at price $p_{t}$ is expected to be impossible, and by Condition 4 of Definition 7.1, $p_{t}=\underline{p}_{t}$. We define the set of demand rationing constraints $R(p, r)$ by

$$
R(p, r)=\left\{y \in \bar{Y} \mid m(y)>p_{t(y)} \text { if } r_{t(y)}=0 \text { and } m(y) \geq p_{t(y)} \text { if } r_{t(y)}=1\right\} .
$$

TheORem 7.3: Let $\left(A^{*}, p^{*}, q^{*}, r^{*}\right)$ be a Drèze equilibrium of the monetary economy subject to price controls $\mathcal{E}=\left(\bar{Y},\left(u_{i}\right)_{i \in I}\right)$. Then $\left(A^{*}, Q\left(p^{*}, q^{*}\right), R\left(p^{*}, r^{*}\right)\right)$ is an expectational equilibrium of $\mathcal{E}$.

Proof: We define $Q^{*}=Q\left(p^{*}, q^{*}\right)$ and $R^{*}=R\left(p^{*}, q^{*}\right)$ and show that $\left(A^{*}, Q^{*}, R^{*}\right)$ satisfies the three conditions of Definition 2.6.

Suppose there is $f \in F$ such that $A^{* f} \notin \delta^{f}\left(Q^{* f}\right)$. Then there is $A^{f} \in \beta^{f}\left(Q^{* f}\right)$ such that $u^{f}\left(A^{f}\right)>u^{f}\left(A^{* f}\right)$. Since $\emptyset \in \beta^{f}\left(Q^{* f}\right)$, it holds that $u^{f}\left(A^{* f}\right) \geq 0$, so $u^{f}\left(A^{f}\right)>0$ and 
$A^{f} \neq \emptyset$. Let

$$
\widetilde{A}^{f}=\left\{(t, m) \in t\left(A^{f}\right) \times \mathbb{R} \mid m=p_{t}^{*}\right\}
$$

be the contracts in $A^{f}$ where the monetary part of the contract has been replaced by the Drèze equilibrium price. For every $t \in t\left(A^{*}\right)$, we have $q_{t}^{*}=0$, since $q_{t}^{*}=1$ implies that $B^{f}\left(p^{*}, q^{*}\right)$ does not contain a contract involving trade $t$. It now follows that $\widetilde{A}^{f} \in B^{f}\left(p^{*}, q^{*}\right)$. Using the definition of $Q^{*}$, we have that $M\left(\widetilde{A}^{f}\right) \leq M\left(A^{f}\right)$, so $u^{f}\left(\widetilde{A}^{f}\right) \geq u^{f}\left(A^{f}\right)>u^{f}\left(A^{* f}\right)$, leading to a contradiction with $A^{* f} \in D^{f}\left(p^{*}, q^{*}\right)$. Consequently, it holds that, for every $f \in F, A^{* f} \in \delta^{f}\left(Q^{* f}\right)$.

A symmetric argument can be used to show that, for every $w \in W, A^{* w} \in \delta^{w}\left(R^{* w}\right)$.

Suppose $Q^{*} \cap R^{*} \neq \emptyset$. Let $(t, m) \in Q^{*} \cap R^{*}$. By definition of $Q^{*}$ and $R^{*}$, it follows that $m=p_{t}^{*}, q_{t}^{*}=1$, and $r_{t}^{*}=1$. This leads to a contradiction with Condition 5 of Definition 7.1. Consequently, it follows that $Q^{*} \cap R^{*}=\emptyset$.

We have shown that $\left(A^{*}, Q^{*}, R^{*}\right)$ is an expectational equilibrium of $\mathcal{E}$.

We show next that the converse of Theorem 8.3 holds as well. For every expectational equilibrium of a monetary economy subject to price controls, there is a Drèze equilibrium with the same equilibrium outcome. For this direction, we need to assume that utility functions are continuous.

TheOREM 7.4: Let $\mathcal{E}=\left(\bar{Y},\left(u^{i}\right)_{i \in I}\right)$ be a monetary economy subject to price controls with continuous utility functions and let $\left(A^{*}, Q^{*}, R^{*}\right)$ be an expectational equilibrium of $\mathcal{E}$. Then there is $\left(p^{*}, q^{*}, r^{*}\right) \in \mathbb{R}^{T} \times\{0,1\}^{T} \times\{0,1\}^{T}$ such that $\left(A^{*}, p^{*}, q^{*}, r^{*}\right)$ is a Drèze equilibrium of $\mathcal{E}$.

Proof: We first define prices $p^{*} \in \mathbb{R}^{T}$. To do so, we divide $T$ in five mutually exclusive subsets $T_{1}, \ldots, T_{5}$. The set of trades that are part of the expectational equilibrium outcome are denoted by $T_{1}$. The set of trades that are not part of an expectational equilibrium outcome, but for which there is an amount of money that respects the price controls and for which neither the firm nor the worker involved expects rationing is given by $T_{2}$. The trades $t$ in $T_{3}, T_{4}$, and $T_{5}$ are such that for every amount of money $m \in\left[\underline{p}_{t}, \bar{p}_{t}\right]$ either the firm or the worker expects rationing. Trades in $T_{3}$ are such that both the worker and the firm expect rationing for some amounts of money, for trades in $T_{4}$ the firm never expects 
rationing, and for trades in $T_{5}$ the worker never expects rationing. More formally, we have

$$
\begin{aligned}
& T_{1}=t\left(A^{*}\right), \\
& T_{2}=\left\{t \in T \backslash t\left(A^{*}\right) \mid Q_{t}^{*} \cup R_{t}^{*} \neq\left[\underline{p}_{t}, \bar{p}_{t}\right]\right\}, \\
& T_{3}=\left\{t \in T \mid Q_{t}^{*} \neq \emptyset, R_{t}^{*} \neq \emptyset, \text { and } Q_{t}^{*} \cup R_{t}^{*}=\left[\underline{p}_{t}, \bar{p}_{t}\right]\right\}, \\
& T_{4}=\left\{t \in T \mid R_{t}^{*}=\left[\underline{p}_{t}, \bar{p}_{t}\right]\right\}, \\
& T_{5}=\left\{t \in T \mid Q_{t}^{*}=\left[\underline{p}_{t}, \bar{p}_{t}\right]\right\} .
\end{aligned}
$$

For every $t \in T_{1}$, let $p_{t}^{*}=m$, where $m$ is such that $(t, m) \in A^{*}$. Moreover, we define $q_{t}^{*}=r_{t}^{*}=0$. For every $t \in T_{2}$, choose an element $p_{t}^{*}$ in $\left[\underline{p}_{t}, \bar{p}_{t}\right] \backslash\left(Q_{t}^{*} \cup R_{t}^{*}\right)$. Again, we define $q_{t}^{*}=r_{t}^{*}=0$. For every $t \in T_{3}$, choose an element $p_{t}^{*}$ in $\operatorname{cl}\left(Q_{t}^{*}\right) \cap \operatorname{cl}\left(R_{t}^{*}\right)$. Since $\left[\underline{p}_{t}, \bar{p}_{t}\right]$ is connected, it follows that $\operatorname{cl}\left(Q_{t}^{*}\right) \cap \operatorname{cl}\left(R_{t}^{*}\right) \neq \emptyset$. Again, we define $q_{t}^{*}=r_{t}^{*}=0$.

For every $t \in T_{4}$ such that $\underline{p}_{t}>-\infty$, define $p_{t}^{*}=\underline{p}_{t}, q_{t}^{*}=0$, and $r_{t}^{*}=1$. For every $t \in T_{4}$ such that $\underline{p}_{t}=-\infty$, define $p_{t}^{*}=\min \left\{m^{w(t)}, \bar{p}_{t}\right\}$ and $q_{t}^{*}=r_{t}^{*}=0$.

For every $t \in T_{5}$ such that $\bar{p}_{t}<+\infty$, define $p_{t}^{*}=\bar{p}_{t}, q_{t}^{*}=1$, and $r_{t}^{*}=0$. For trades $t \in T_{5}$ such that $\bar{p}_{t}=+\infty$, we choose the price to be sufficiently high such that a contract for that price is never chosen by the firm involved. More precisely, for every $f \in F$, we define

$$
\widetilde{m}^{f}=\sum_{t \in\left(T_{1} \cup T_{2} \cup T_{3} \cup T_{4}\right) \cap T^{f}} \max \left\{0,-p_{t}^{*}\right\} .
$$

For every $t \in T_{5}$ such that $\bar{p}_{t}=+\infty$, we define $p_{t}^{*}=\max \left\{\widetilde{m}^{f}+\max \left\{0, m^{f}\right\}, \underline{p}_{t}\right\}$ and $q_{t}^{*}=r_{t}^{*}=0$.

We now verify that $\left(A^{*}, p^{*}, q^{*}, r^{*}\right)$ satisfies the five conditions of Definition 7.1.

Let some $f \in F$ be given. By the definition of $p_{t}^{*}$ and $q_{t}^{*}$ for $t \in T_{1}$, it follows immediately that $A^{* f} \in B^{f}\left(p^{*}, q^{*}\right)$.

Suppose $A^{* f} \notin D^{f}\left(p^{*}, q^{*}\right)$, so there is $A^{f} \in B^{f}\left(p^{*}, q^{*}\right)$ such that $u^{f}\left(A^{f}\right)>u^{f}\left(A^{* f}\right)$. We show first that $t\left(A^{f}\right) \cap T_{5}=\emptyset$. Consider some $t \in T_{5}$. If $\bar{p}_{t}<+\infty$, then $q_{t}^{*}=1$, so $t \notin t\left(A^{f}\right)$. Consider the case where $\bar{p}_{t}=+\infty$. If there is $t \in T_{5}$ such that $t \in t\left(A^{f}\right)$, then

$$
\begin{aligned}
M\left(A^{f}\right) & =\sum_{t \in t\left(A^{f}\right)} p_{t}^{*} \\
& =\sum_{t \in\left(T_{1} \cup T_{2} \cup T_{3} \cup T_{4} \cup T_{5}\right) \cap t\left(A^{f}\right)} p_{t}^{*} \\
& \geq-\widetilde{m}^{f}+\sum_{t \in T_{5} \cap t\left(A^{f}\right)} p_{t}^{*} \\
& \geq-\widetilde{m}^{f}+\widetilde{m}^{f}+\max \left\{0, m^{f}\right\} \\
& \geq m^{f},
\end{aligned}
$$

so $u^{f}\left(A^{f}\right) \leq u^{f}(\emptyset) \leq u^{f}\left(A^{* f}\right)$. It follows that $t\left(A^{f}\right) \cap T_{5}=\emptyset$. For every $\varepsilon>0$, for every $t \in t\left(A^{* f}\right) \cap T_{3}$, from the fact that $p_{t}^{*} \in \operatorname{cl}\left(R_{t}^{*}\right)$, there exists $\widetilde{p}_{t} \in R_{t}^{*}$ such that $\left|\widetilde{p}_{t}-p_{t}^{*}\right| \leq \varepsilon$. From Condition 3 in Definition 2.6 of an expectational equilibrium, we have that $\widetilde{p}_{t} \notin Q_{t}^{*}$. We define

$$
\widetilde{A}^{f}=\left\{y \in A^{f} \mid t(y) \notin T_{3}\right\} \cup\left\{y \in A^{f} \mid t(y) \in T_{3} \text { and } m(y)=\widetilde{p}_{t(y)}\right\},
$$


so $\widetilde{A}^{f}$ results from $A^{f}$ by changing the price of trades $t$ in $t\left(A^{f}\right) \cap T_{3}$ from $p_{t}^{*}$ to $\widetilde{p}_{t}$. Since $\widetilde{A}^{f} \cap Q^{* f}=\emptyset$, it holds that $\widetilde{A}^{f} \in \beta^{f}\left(Q^{* f}\right)$. By continuity of $u^{f}$ it holds that for $\varepsilon>0$ sufficiently small, $u^{f}\left(\widetilde{A}^{f}\right)>u^{f}\left(A^{* f}\right)$, contradicting that $A^{* f} \in \delta^{f}\left(Q^{* f}\right)$. Consequently, it holds that $A^{* f} \in D^{f}\left(p^{*}, q^{*}\right)$.

Let some $w \in W$ be given. By the definition of $p_{t}^{*}$ and $r_{t}^{*}$ for $t \in T_{1}$, it follows immediately that $A^{* w} \in B^{w}\left(p^{*}, r^{*}\right)$.

Suppose $A^{* w} \notin D^{w}\left(p^{*}, r^{*}\right)$. Then there is $A^{w}=\left\{\left(t, p_{t}^{*}\right)\right\} \in B^{w}\left(p^{*}, r^{*}\right)$ such that $u^{w}\left(\left\{\left(t, p_{t}^{*}\right)\right\}\right)>u^{w}\left(A^{* w}\right)$. Since $A^{w} \neq A^{* w}$, it holds that $t \notin T_{1}$. From $A^{w} \notin \beta^{w}\left(R^{* w}\right)$, it follows that $p_{t}^{*} \in R_{t}^{*}$, so $t \notin T_{2} \cup T_{5}$. If $t \in T_{4}$, then either $\underline{p}_{t}>-\infty$ and $r_{t}^{*}=1$, contradicting $A^{w} \in B^{w}\left(p^{*}, r^{*}\right)$, or $\underline{p}_{t}=-\infty$, so $p_{t}^{*}=\min \left\{m^{w}, \bar{p}_{t}\right\}$ and it holds that $u^{w}\left(A^{w}\right) \leq u^{w}(\emptyset) \leq u^{w}\left(A^{* w}\right)$, leading to a contradiction as well. The only possibility is that $t \in T_{3}$.

Suppose $t \in T_{3}$. From $A^{w} \notin \beta^{w}\left(R^{* w}\right)$, it follows that $p_{t}^{*} \in R_{t}^{*}$. Since $p_{t}^{*} \in \operatorname{cl}\left(Q_{t}^{*}\right)$, for every $\varepsilon>0$, there exists $\widetilde{p}_{t} \in Q_{t}^{*}$ such that $\left|\widetilde{p}_{t}-p_{t}^{*}\right| \leq \varepsilon$. From Condition 3 in the definition of an expectational equilibrium, we have that $\widetilde{p}_{t} \notin R_{t}^{*}$. It follows that $\left\{\left(t, \widetilde{p}_{t}\right)\right\} \in \beta^{w}\left(R^{* w}\right)$ and, by continuity of $u^{w}$, for $\varepsilon>0$ sufficiently small, $u^{w}\left(\left\{\left(t, \widetilde{p}_{t}\right)\right\}\right)>u^{w}\left(A^{* w}\right)$, leading to a contradiction. Consequently, it holds that $t \notin T_{3}$.

We conclude that $A^{* w} \in D^{w}\left(p^{*}\right)$.

Conditions 3, 4, and 5 of Definition 7.1 follow immediately from our definition of $p^{*}$, $q^{*}$, and $r^{*}$.

\section{Conclusion}

The connection between concepts like competitive equilibrium where agents optimize taking the key parameters of the environment as given and concepts like stability where agents form groups to reallocate their resources has a longstanding tradition in economics. In matching models where agents can make monetary transfers, the equivalence of the two approaches is well-known. In the stream of the matching literature where agents cannot make monetary transfers or where monetary transfers are restricted like in the marriage problem problem of Gale and Shapley (1962) or the model of matching with contracts of Hatfield and Milgrom (2005), little was known about such a connection so far. When discussing the connection between competitive markets and stability in the context of the marriage model, Shapley and Scarf (1974), p. 35, remark that: "It does not appear to be possible to set up a conventional market for this model, in such a way that a competitive price equilibrium will exist and lead to an allocation in the core."

This paper introduces a new notion of competitive equilibrium, called expectational equilibrium, in a very general specification of the many-to-one matching with contracts 
model. An important feature of the specification is that the set of contracts is allowed to be uncountable. At an expectational equilibrium agents have expectations about contracts for which trade is possible and contracts for which such is not the case. In equilibrium, agents optimize by signing those contracts that maximize their utility given their expectations about trading opportunities. In equilibrium, expectations are required to be rational. If an agent expects a trading constraint for a certain contract, then the agent on the other side expects no such constraint and is indeed not choosing the contract.

For two special cases of the model without or with limited possibilities to make monetary transfers, school choice as studied by Abdulkadiroğlu, Che, and Yasuda (2015) and Azevedo and Leshno (2016) and matching under price controls as studied in Herings (2018), expectational equilibrium leads to the same equilibrium outcomes as the concepts studied in these two papers, market clearing cutoff and Drèze equilibrium, respectively. For models with unlimited monetary transfers, expectational equilibrium outcomes coincide with standard competitive equilibrium outcomes. Expectational equilibrium thereby unifies all the existing approaches in the literature.

There are several stability concepts in matching models. For the many-to-one model, there is pairwise stability, stability, the core, and the strong core. Moreover, in general these concepts make different predictions. Expectational equilibrium is shown to coincide with stability. This holds under very general conditions. In fact, this equivalence holds for the entire class of models studied in this paper and neither requires preferences to be strict nor assumptions like substitutability or continuity.

Existence of expectational equilibrium holds under the same conditions as those for which the set of stable outcomes is non-empty. A well-known sufficient condition is substitutability, which is stated in this paper for any two nested sets of contracts that have finitely many elements. Together with continuity of the utility functions, this leads to an existence result. Interestingly, we therefore obtain an equilibrium existence result for cases where money is not required to be perfectly divisible. Already in models of partial equilibrium with a smallest unit of account, market clearing prices obviously may not exist. Expectational equilibria do exist in these cases and they make exactly the prediction one would intuitively expect. More generally, expectational equilibria exist in the assignment model of Shapley and Shubik (1971) when prices are denominated in a smallest unit of account, even when valuations are not.

Other classes of models where it might prove fruitful to study expectational equilibria are those where agents face hard financial constraints. In such models, competitive equilibria may not exist, even when preferences are quasi-linear in money and substitutable. To address these existence issues, Gul, Pesendorfer, and Zhang (2018) introduce randomized competitive equilibria and Herings and Zhou (2019) introduce quantity-constrained 
competitive equilibria. It is also promising to study expectational equilibria in matching models with distributional constraints, see Kamada and Kojima (2015), where existence of stable outcomes cannot be guaranteed. Nöldeke and Samuelson (2018) show that many results in matching models with a finite number of agents, carry over to the case with a continuum of agents. Such issues can also be examined for expectational equilibria.

It is straightforward to formulate the notion of expectational equilibrium to extensions of many-to-one matching models like many-to-many matching models or matching models with networks of trading agents. The extension could also cover the case where agents could choose from uncountable sets of contracts, thereby bringing the matching models close to standard competitive equilibrium models. Already in the many-to-many case, there are many cooperative solution concepts, see Echenique and Oviedo (2006), Konishi and Ünver (2006), and Klaus and Walzl (2009). How expectational equilibria relate to such notions is an interesting direction for future research.

\section{References}

AbdulkadiroĞLu, A., Y.K. Che, And Y. Yasuda (2015), "Expanding "Choice" in School Choice," American Economic Journal: Microeconomics, 7, 1-42.

Andersson, T., And L.G. Svensson (2014), "Non-manipulable House Allocation with Rent Control," Econometrica, 82, 507-539.

Azevedo, E.M., And J.D. Leshno (2016), "A Supply and Demand Framework for Two-sided Matching Markets," Journal of Political Economy, 124, 1235-1268.

Aziz, H., M. Brill, And P. Harrenstein (2013), "Testing Substitutability of Weak Preferences," Mathematical Social Sciences, 66, 91-94.

BÉNASSY, J.-P. (1975), "Neo-Keynesian Disequilibrium Theory in a Monetary Economy," Review of Economic Studies, 42, 503-523.

Crawford, V.P., And E.M. Knoer (1981), "Job Matching with Heterogeneous Firms and Workers," Econometrica, 49, 437-450.

Demange, G., D. Gale, and M. Sotomayor (1986), "Multi-Item Auctions," Journal of Political Economy, 94, 863-872.

DrÈze, J.H. (1975), "Existence of an Exchange Equilibrium under Price Rigidities," International Economic Review, 16, 301-320.

Dubey, P., J. Geanakoplos, and M. Shubik (2005), "Default and Punishment in General Equilibrium," Econometrica, 73, 1-37.

Echenique, F. (2012), "Contracts versus Salaries in Matching," American Economic Review, 102, 594601.

Echenique, F., And J. Oviedo (2006), "A Theory of Stability in Many-to-many Matching Markets," Theoretical Economics, 1, 233-273. 
Fleiner, T., R. Jagadeesan, Z. Jankó, and A. Teytelboym (2019), "Trading Networks with Frictions," Econometrica, 87, 1633-1661.

Gale, D., And L.S. Shapley (1962), "College Admissions and the Stability of Marriage," American Mathematical Monthly, 69, 9-15.

Gul, F., W. Pesendorfer, And M. Zhang (2018), "Market Design and Walrasian Equilibrium," Working Paper, 1-44.

Gul, F., And E. Stacchetti (1999), "Walrasian Equilibrium with Gross Substitutes," Journal of Economic Theory, 87, 95-124.

Hatfield, J.W., And F. Kojima (2010), "Substitutes and Stability for Matching with Contracts," Journal of Economic Theory, 145, 1704-1723.

Hatfield, J.W., S.D. Kominers, A. Nichifor, M. Ostrovsky, and A. Westkamp (2013), "Stability and Competitive Equilibrium in Trading Networks," Journal of Political Economy, 121, 966-1005.

Hatfield, J.W., S.D. Kominers, A. Nichifor, M. Ostrovsky, and A. Westkamp (2019), "Full substitutability," Theoretical Economics 14, 1535-1590.

Hatfield, J.W., And P. Milgrom (2005), "Matching with Contracts," American Economic Review, 95, 915-935.

Hatfield, J.W., C.R. Plott, and T. Tanaka (2012), "Understanding Price Controls and Nonprice Competition with Matching Theory," American Economic Review, Papers 83 Proceedings, 102, 371375 .

Hatfield, J.W., C.R. Plott, And T. Tanaka (2016), "Price Controls, Non-price Quality Competition, and the Nonexistence of Competitive Equilibrium," Games and Economic Behavior, 99, $134-163$.

Herings, P.J.J. (2018), "Equilibrium and Matching under Price Controls," Journal of Economic Theory, $177,222-244$.

Herings, P.J.J., And Y. Zhou (2019), "Competitive Equilibria in Matching Models with Financial Constraints," GSBE Research Memorandum 19/07, Maastricht University, Maastricht, pp. 1-39.

Kamada, Y., And F. KoJima (2015), "Efficient Matching under Distributional Constraints: Theory and Applications," American Economic Review, 105, 67-99.

Kaneko, M. (1982), "The Central Assignment Game and the Assignment Markets," Journal of Mathematical Economics, 10, 205-232.

Kelso, A.S., Jr., And V.P. Crawford (1982), "Job Matching, Coalition Formation, and Gross Substitutes," Econometrica, 50, 1483-1504.

Klaus, B., And M. Walzl (2009), "Stable Many-to-many Matchings with Contracts," Journal of Mathematical Economics, 45, 422-434.

Konishi, H., And M.U. Ünver (2006), "Credible Group Stability in Many-to-many Matching Problems," Journal of Economic Theory, 129, 57-80.

NöLdeke, G., AND L. SAmuelson (2018), "The Implementation Duality," Econometrica, 86, 12831324. 
Plott, C., R. Roll, H. Seo, And H. Zhao (2019), "Tick Size, Price Grids and Market Performance: Stable Matches as a Model of Market Dynamics and Equilibrium," Games and Economic Behavior, 118, 7-28.

Richter, M., And A. Rubinstein (2015), "Back to Fundamentals: Equilibrium in Abstract Economies," American Economic Review, 105, 2570-2594.

Roth, A.E. (1984), "Stability and Polarization of Interests in Job Matching," Econometrica, 52, 47-58.

Shapley, L.S., AND H.E. Scarf (1974), "On Cores and Indivisibility," Journal of Mathematical Economics, 1, 23-37.

Shapley, L.S., And M. Shubik (1971), "The Assignment Game I: The Core," International Journal of Game Theory, 1, 111-130.

Sotomayor, M.A.O. (1999), "Three Remarks on the Many-to-many Stable Matching Problem," Mathematical Social Sciences, 38, 55-70.

Sun, N., AND Z. YAng (2006), "Equilibria and Indivisibilities: Gross Substitutes and Complements," Econometrica, 74, 1385-1402.

TAlman, A.J.J., AND Z. YANG (2008), "A Dynamic Auction for Differentiated Items under Price Rigidities," Economics Letters, 99, 278-281.

Younès, Y. (1975), "On the Role of Money in the Process of Exchange and the Existence of a NonWalrasian Equilibrium," Review of Economic Studies, 42, 489-501. 